\title{
CFD Computations for a Generic High-Lift Configuration Using TetrUSS
}

\author{
Mohagna J. Pandya ${ }^{*}$ and Khaled S. Abdol-Hamid ${ }^{\dagger}$ \\ NASA Langley Research Center, Hampton, VA, 23681, USA \\ Edward B. Parlette \\ ViGYAN, Hampton, VA, 23681, USA
}

\begin{abstract}
Assessment of the accuracy of computational results for a generic high-lift trapezoidal wing with a single slotted flap and slat is presented. The paper is closely aligned with the focus of the $1^{\text {st }}$ AIAA CFD High Lift Prediction Workshop (HiLiftPW-1) which was to assess the accuracy of CFD methods for multi-element high-lift configurations. The unstructured grid Reynolds-Averaged Navier-Stokes solver TetrUSS/USM3D is used for the computational results. USM3D results are obtained assuming fully turbulent flow using the Spalart-Allmaras (SA) and Shear Stress Transport (SST) turbulence models. Computed solutions have been obtained at seven different angles-of-attack ranging from $6^{\circ}-37^{\circ}$. Three grids providing progressively higher grid resolution are used to quantify the effect of grid resolution on the lift, drag, pitching moment, surface pressure and stall angle. SA results, as compared to SST results, exhibit better agreement with the measured data. However, both turbulence models under-predict upper surface pressures near the wing tip region.
\end{abstract}

\section{Nomenclature}

$\begin{array}{ll}A V G & =\text { Average } \\ C F D & =\text { Computational Fluid Dynamics } \\ C P U & =\text { axial force coefficient } \\ C_{A F} & =\text { drag coefficient } \\ C_{D} & =\text { lift coefficient } \\ C_{L} & =\text { pitching moment coefficient } \\ C_{M} & =\text { normal force coefficient } \\ C_{N} & =\text { pressure coefficient } \\ C_{p} & =\text { rolling moment coefficient } \\ C_{R M} & =\text { side force coefficient } \\ C_{Y} & =1 \text { st High Lift Prediction Workshop } \\ C_{Y M} & =\text { freestream Mach number } \\ \text { HiLiftPW-1 } & =\text { number of cells in a given grid } \\ M_{\infty} & =\text { mean flow or turbulence model residual error sum } \\ N & =\text { Spalart-Allmaras turbulence model } \\ R & =\text { Wind Tunnel } \\ \text { SA } & =\text { x-coordinate over the configuration with control surfaces deployed, inch } \\ \text { SST } & =\text { y-coordinate over the configuration with control surfaces deployed, inch } \\ \text { WT } & =\text { normalized distance in boundary layer } \\ X & =\text { angle-of-attack, degree } \\ Y & \end{array}$

\footnotetext{
${ }^{*}$ Research Aerospace Engineer, Configuration Aerodynamics Branch, Mail Stop 499, AIAA Senior Member

${ }^{\dagger}$ Senior Aerospace Engineer, Configuration Aerodynamics Branch, Mail Stop 499, AIAA Associate Fellow

* Research Engineer, 30 Research Drive
} 


\section{Introduction}

$\mathrm{T}$ HE $1^{\text {st }}$ AIAA CFD High Lift Prediction Workshop (HiLiftPW-1) was organized on June 26-27 2010 in association with the $28^{\text {th }}$ AIAA Applied Aerodynamics Conference at Chicago, IL. The workshop was organized to facilitate the assessment of current CFD flow solvers to numerically predict the aerodynamic performance of swept medium-to-high aspect ratio wings in landing/take-off (high-lift) configurations. Objectives of the workshop ${ }^{1}$ were to (1) Assess numerical prediction capability of current generation CFD codes for swept, medium/high aspect ratio wings in landing/take-off (high-lift) configurations, (2) Develop practical modeling guidelines for CFD prediction of high-lift flowfields, (3) Advance the understanding of high-lift flow physics to enable development of more accurate prediction methods and tools, (4) Provide an impartial forum for evaluating the effectiveness of existing computer codes and modeling techniques, (5) Enhance CFD prediction capability for practical high-lift aerodynamic design and optimization, and (6) Identify areas needing additional research and development.

The NASA Trapezoidal (Trap) wing-body geometry was selected as a generic high-lift configuration for the workshop. The configuration consists of a three-element wing with a full-span slat and a full-span flap. Trap wing layout and key geometric and reference parameters have been presented in Ref. 1. Two configurations, namely, Configuration 1 (slat deflected at $30^{\circ}$ and flap deflected at $25^{\circ}$ ) and Configuration 8 (slat deflected at $30^{\circ}$ and flap deflected at $20^{\circ}$ ) were used in the workshop studies. These configurations have been extensively tested ${ }^{2,3}$ in the NASA Langley $14 \times 22$ foot wind tunnel facility. Forces, moments, and surface pressures measured in these tests were made available to workshop participants and have been used to assess the accuracy of numerical predictions.

Computational grids play a very important role in accurately resolving the complex flowfield that is characterized by shedding of wakes from various elements of the wing and merger of wakes with the boundary layers. Chaffin and Pirzadeh ${ }^{4}$ identified the grid resolution requirements needed to capture the flow physics at various points on the lift curve of the trapezoidal wing configuration and demonstrated improvements to the lift prediction due to grid refinement. For the HiLiftPW-1 workshop, a specific set of gridding guidelines were developed and published prior to the workshop to establish consistency between various grid systems used by workshop participants. The workshop organizing committee made available a total of nine structured and unstructured grid systems. Twenty-one participants from eighteen organizations submitted 39 datasets of CFD results. Combined results from all participants are compared with the experimental data and statistically analyzed in Ref. 5.

Two of the workshop datasets were generated using the NASA TetrUSS ${ }^{6,7}$ flow analysis system. One of these datasets $^{8}$ used four variants of the $\mathrm{k}-\omega$ turbulence model whereas another dataset used the SA model. This paper documents the results from the TetrUSS dataset based on the SA model. The paper also assesses the sensitivity of the numerical results to turbulence models by including the results from the SST two-equation model. The paper is organized with Section II presenting an overview of the TetrUSS system with an emphasis on the component codes used for grid generation and flow solution. Section III presents some highlights of the computational approach adopted for the present study. Computational results and their comparison with the wind tunnel measurements are discussed in Section IV.

\section{Overview of TetrUSS}

The NASA Tetrahedral Unstructured Software System (TetrUSS) was developed during 1990s to provide a rapid aerodynamic analysis and design capability for applied aerodynamicists. The system is comprised of loosely integrated, user-friendly software that enables the application of advanced Euler and Navier-Stokes tetrahedral finite volume technology to complex aerodynamic problems. The system consists of component software for setting up geometric surface definitions (GridTool), generating tetrahedral grids (VGRID), computing Euler and Navier-Stokes flow solutions (USM3D), and extracting meaningful information from analysis of results (SimpleView). An overview of the capabilities of TetrUSS system in early 2000 is presented in Ref. 6. Reference 7 details the latest enhancements to TetrUSS system and its application for the NASA Constellation program. The system also allows for imposing design or aeroelastic shape changes by interfacing with other codes, such as CDISC ${ }^{9}$. The salient features of the VGRID grid generator and USM3D flow solver are presented below.

\section{A. Grid Generator}

VGRID is a tetrahedral grid generator based on the Advancing Front Method ${ }^{10}$ (AFM) for generation of the 'inviscid' field cells and the Advancing Layers $\operatorname{Method~}^{11}$ (ALM) for generation of thin-layered 'viscous' cells. Both techniques are based on a marching process in which tetrahedral cells grow from an initial front (triangular surface mesh) and gradually accumulate in the field around the subject geometry. Unlike the conventional AFM, which 
introduces cells in the field in a totally unstructured manner, the ALM generates layers of thin tetrahedral cells in a more orderly fashion (one layer at a time) while maintaining the flexibility of AFM.

A new approach for the distribution of grid points on the surface and in the volume has been developed and incorporated in VGRID ${ }^{12}$. In addition to the point and line sources, the new approach uses surface and volume sources for automatic curvature-based grid sizing and convenient point distribution in the volume. A new exponential growth function produces smoother and more efficient grids and provides superior control over the distribution of grid points in the field. Anisotropic grid stretching is still available for all types of sources for grid economy. Once the advancing front process is completed in VGRID, an additional post-processing step is required using POSTGRID to close any open pockets and to improve grid quality.

VGRID input files are generated by an interactive geometry manipulation program, GridTool ${ }^{13}$. It can import surface definitions from IGES files (NURBS surfaces and NURBS curves) and from PLOT3D files (point definitions) and manipulate them to define necessary geometric (surface patches) and grid-spacing (sources) parameters. It uses OpenGL for 3D graphics. The graphical interface is based on the Fast Light Toolkit. GridTool is available for Mac and Linux systems.

\section{B. Flow Solver}

The USM3 $\mathrm{D}^{14,15}$ code is a parallelized tetrahedral cell-centered, finite volume Navier-Stokes flow solver. The term cell centered means that the finite volume flow equations are solved at the centroid of each tetrahedral cell. Inviscid flux quantities are computed across each tetrahedral cell face using various upwind schemes. These schemes include Roe's flux difference splitting (FDS) scheme, Liou's advection upstream splitting method (AUSM+), Toro's HLLC scheme, and Edward's low diffusion flux splitting schemes (LDFSS). Spatial discretization is accomplished by a novel reconstruction process, based on an analytical formulation for computing solution gradients within tetrahedral cells. The solution is advanced in time by a second-order Newton time step scheme $^{16}$, or to a steady-state condition by an implicit backward-Euler scheme.

USM3D supports an array of useful boundary conditions (BCs). It contains the standard BCs of flow tangency or no-slip on solid surfaces, characteristic inflow/outflow for subsonic boundaries, and freestream inflow and extrapolation outflow for supersonic flow. It also contains some additional special BCs for jet exhaust and intake, a propeller/rotor actuator disk model, and passive porosity ${ }^{17}$.

Several turbulence models are available within USM3D: the Spalart-Allmaras (SA) one-equation model ${ }^{18}$, the two-equation $k$ - $\varepsilon$ turbulence model, the Menter Shear Stress Transport (SST) two-equation model ${ }^{19}$, and the nonlinear Algebraic Reynolds Stress Models (ARSM) of Girimaji and Shih/Zhu/Lumley ${ }^{20}$. Detached Eddy Simulation (DES) has been implemented in all of the turbulence models. A capability to trip the flow at specified locations on aerodynamic surfaces has been implemented for the $k-\varepsilon$ turbulence model, but fully turbulent flow is assumed for the results to follow. USM3D has capabilities for dynamic grid motion and overset grids ${ }^{21}$.

\section{Computational Approach}

In this section, details of the computational grids and numerical approach are presented. Various convergence criteria adopted to ensure solution convergence will be described and a representative plots of solution convergence will be shown. A systematic grid convergence study was not performed for Configuration 8. Therefore, investigations are only presented for Configuration 1. In the present study, slat and flap support brackets have not been modeled. The effect of brackets on the flow solution is summarized in Ref. 5.

\section{A. Details of Grid}

Present computations are based on unstructured tetrahedral grid family that is designated as the UT4 grid system $^{1,5}$ in the families of grids distributed to the HiLiftPW-1 participants. This grid system is suitable for cellcentered flow solvers. Three different grids (coarse, medium, and fine) have been generated to facilitate gridconverged solutions. The grids were generated using TetrUSS grid generation tools GridTool ${ }^{13}$ and VGRID ${ }^{12}$.

Grids in the present study have been generated following the guidelines developed ${ }^{4}$ for accurate computations of three-dimensional high-lift configurations. Grid spacing control in the previous study was achieved in a very laborintensive manner by an arrangement of multiple line sources as the VGRID version at that time lacked efficient surface and volume sources. For the present study, grid spacing control was achieved predominantly by the surface and volume sources. Smooth distribution of the surface mesh was achieved by the use of surface sources. These sources also permit maintenance of consistent grid point distribution for a specified height above a surface. The specification of finer grid spacing along wake paths was achieved by the use of surface sources. Cylindrical volume 
Table 1. Grid statistics for the Trap Wing Configuration 1

\begin{tabular}{|c|c|c|c|}
\hline Grid & Total number of cells & $\begin{array}{c}\text { Number of cells in } \\
\text { viscous layer }\end{array}$ & $\begin{array}{c}\text { Number of } \\
\text { boundary faces }\end{array}$ \\
\hline Coarse & $7,237,190$ & $5,861,814$ & 108,006 \\
\hline Medium & $21,738,311$ & $15,339,447$ & 278,590 \\
\hline Fine & $62,644,381$ & $37,230,375$ & 668,822 \\
\hline
\end{tabular}

sources were used to maintain near-constant grid spacing in the cove region and in the thin gaps between the slat, main wing, and flap.

Farfield boundaries were located at 100 times the mean aerodynamic chord of the wing. The initial average normal spacing to viscous wall in terms of $y+$ coordinate is $1,2 / 3$, and $4 / 9$ for the coarse, medium, and fine grids, respectively. Table 1 outlines additional details of the grids. Figure 1 shows the views of all three grids on the configuration surface and in a cross-sectional streamwise plane.

\section{B. Solution Development and Convergence}

All solutions reported in the present study were computed using Roe's flux difference splitting method and without applying any flux limiter. Flow was assumed to be fully turbulent. Two turbulence models, namely, the $\mathrm{SA}^{18}$ and the SST ${ }^{19}$ models were used in the present computations. Mean flow and turbulence model equations were solved in a decoupled fashion. In the precursor studies, not reported herein, it was established that the solutions were insensitive to the manner in which they were advanced in time (steady-state versus $2^{\text {nd }}$ order time-accurate) and to the prescription of an initial state (freestream condition versus converged solution at a lower angle-of-attack). Based on theses findings all solutions were obtained assuming steady-state using the implicit backward-Euler scheme. Solutions at various angles-of-attack were computed from an initial state corresponding to the freestream condition.

Solution convergence was evaluated by monitoring variations in all six longitudinal and lateral force and moment aerodynamic coefficients. A solution was considered converged when fluctuations in these coefficients were reduced to less than $0.5 \%$ of their respective average values calculated over the previous 2000 iterations. Additionally, all solutions were required to have the cumulative mean flow residual errors reduced by at least three orders of magnitude and turbulence model residual errors reduced by at least two orders of magnitude. Figure 2 presents convergence histories for Configuration 1 at a freestream Mach number of 0.2 and angle-of-attack of 28 degrees for the SA model. It is a typical example of solution convergence for this configuration at various angles-ofattack. A script-based automated process was used to set up solution input parameters, monitor convergence, and analyze and post-process all the solutions.

\section{Results and Discussion}

All computations presented in this study have been made at a freestream Mach number of 0.2 , freestream Reynolds number of $4.3 \times 10^{6}$ (corresponding to mean aerodynamic chord of the wing), and freestream temperature of $520^{\circ} \mathrm{R}$. Solutions have been computed at seven different angles-of-attack, namely, $6^{\circ}, 13^{\circ}, 21^{\circ}, 28^{\circ}, 32^{\circ}, 34^{\circ}$, and $37^{\circ}$. Solutions at each angle-of-attack have been generated using the SA and SST turbulence models. For each of these models, computations have been performed using coarse, medium, and fine grids to assess grid-convergence. Assessment of the accuracy of computed solutions is made by comparison with wind tunnel measurements. Specifically, longitudinal force and moment coefficients (lift, drag, and pitching moment) on the entire configuration, as well as pressure coefficient distributions at certain locations on the configuration surface, are compared.

\section{A. Longitudinal Force and Moment Coefficients}

Figure 3 displays the comparison of SA- and SST-based computed and measured lift coefficient at various angles-of-attack. It is evident that the computed lift coefficient based on coarse grid is significantly different from that obtained using medium and fine grids at all angles-of-attack. It can also be seen that the computed stall angle (angle-of-attack at $\mathrm{C}_{\mathrm{Lmax}}$ ) varies with grid refinement for both turbulence models. For the SA model, the $\mathrm{C}_{\mathrm{Lmax}}$ condition in the coarse, medium, and fine grid computations is observed at an angle-of-attack of $30^{\circ}, 32^{\circ}$, and $34^{\circ}$, respectively. For the SST model, the $\mathrm{C}_{\mathrm{Lmax}}$ condition in the coarse, medium, and fine grid computations is observed at an angle-of-attack of $28^{\circ}, 28^{\circ}$, and $32^{\circ}$, respectively. Lift coefficient values from the SST model are lower than those from the SA model and wind tunnel measurements. SST model stalls at lower angle-of-attack as well due to an early onset of large separation region on the wing that will be discussed later. 
Comparisons of drag and pitching moment coefficients from SA and SST model based computations and wind tunnel measurements are presented in Fig. 4 and Fig. 5, respectively. The SST model under predicts the drag coefficient in the angle-of-attack range of $13^{\circ}-26^{\circ}$. It is also noted from Fig. 4 that the SST medium and fine grid solutions almost overlay each other, indicating that the SST model based drag values may not yield closer agreement with the measurements using yet finer grids. It can be seen from Fig. 5 that SST model computed pitching moment values are more sensitive to grid resolution. In addition, the SST model significantly under predicts absolute values of pitching moment, even with the fine grid. The medium and fine grid drag coefficient values for the SA model are in very good agreement with the measurements. The SA model somewhat under predicts absolute values of pitching moment even with the fine grid. However, longitudinal force and moment coefficients from the SA model show a much closer agreement with the wind tunnel measurements over the entire range of angle-of-attack as compared to those from the SST model.

Figure 6 presents the grid sensitivity of longitudinal forces and moment computed using the SA model, where, variations of $C_{L}, C_{D}$, and $C_{M}$ with respect to the square of representative grid spacing $\left(\mathrm{N}^{-2 / 3} ; \mathrm{N}\right.$ is total number of cells) at angles-of-attack of $13^{\circ}$ and $28^{\circ}$ are displayed. The lack of linear variation with respect to grid spacing that is observed for all three coefficients underlines the somewhat aberrant behavior for a spatially second-order computational method. The drag coefficient shows the least degree of grid sensitivity for both angles-of-attack. It is also noted that all three coefficients exhibited similar grid sensitivity at other angles-of-attack (not shown).

Individual contributions from various components of the configuration, namely, the slat, main wing, flap, and fuselage, to the total lift and total drag are plotted in Fig. 7 and Fig. 8, respectively, for the entire range of angles-ofattack. As expected, the main wing is the primary contributor to the lift. The slat, flap, and fuselage produce lift in decreasing order. Drag is mostly produced by the main wing. The flap and fuselage contribute to drag as well, but in smaller amounts. As expected, the slat produces negative drag (thrust).

\section{B. Surface Pressure}

Extensive measurements of the surface pressure were conducted during the wind tunnel test. Surface pressures were measured at 43 cross-sections over the slat, main wing, flap and body using a total of 841 pressure ports, as shown in Fig. 9(a). Pressure data for the USM3D SA model results at all of these locations was submitted for the HiLiftPW-1. In the present study, computational results are compared with the measurements at four streamwise cross-sections and one spanwise cross-section. These cross-sections are 50\% (ST50), 85\% (ST85), 95\% (ST95), and 98\% (ST98) of the span for all three elements of the wing and one forward span station (flapfwdspan) on the flap. These locations are shown in Fig. 9(b).

Figures 10 and 11 present the effect of grid refinement on the surface pressures derived from the SA and SST models at an angle-of-attack of $13^{\circ}$. In these figures computed surface pressures from the coarse, medium, and fine grid SA solutions (Fig. 10) and SST solutions (Fig. 11) are compared with the measured surface pressures at stations ST50, ST85, ST95, and ST98. Surface pressures from the SA model at ST50 and ST85 show little effect of grid refinement. At these two stations, medium and fine grid surface pressures are almost identical and agree very well with the measured data. However, further outboard, especially at station ST98, grid resolution effect can be clearly seen on the main wing and flap. SA computations match satisfactorily with the measurements at ST95 over the slat, flap, and most of the main wing except the cove region. However, at station ST98 even fine grid surface pressures show poor agreement with the measured surface pressures over most of the main wing and flap upper surface. SST solutions (Fig. 11) display an increased sensitivity to grid resolution at all four stations, specifically on the flap. SST surface pressures on the upper surface are generally lower than the measured data, resulting in lower lift as seen in Fig. 3. A trend common to both the SA and SST models is that the difference between medium and fine grid surface pressures is generally much smaller than the difference between the coarse and medium grid surface pressures everywhere except at ST98. At station ST98, computed surface pressures from the medium and fine grids differ significantly for both models, indicating the need for further refinement of the tip region of the main wing and the flap.

Figures 12 and 13 display the grid refinement effect on the SA and SST surface pressures at an angle-of-attack of $28^{\circ}$. SA results display similar grid resolution sensitivities and correlation with the measured data as those observed for an angle-of-attack of $13^{\circ}$. It is evident from Fig. 13 that the surface pressures from SST solutions at stations ST50 and ST85 display a higher degree of grid-convergence as well as agreement with the measured data as compared to the same at angle-of-attack $13^{\circ}$. This is also reflected in Fig. 3(b), where agreement of the SST model lift coefficient with the measured data at a $28^{\circ}$ angle-of-attack is much better than that at lower angles-of-attack.

A direct comparison of fine grid SA and SST solutions with the wind tunnel measurements is made in Fig. 14. The figure shows surface pressures at stations ST50 and ST98 for angles-of-attack $6^{\circ}, 13^{\circ}, 21^{\circ}, 28^{\circ}$, and $34^{\circ}$. SA 
model surface pressures are generally in closer agreement with the measurements. However, both models poorly predict the measured data at ST98 near wing tip, at least on the grid used for the present computations. This trend has also been observed in similar studies employing different computational methods and grids ${ }^{5}$. The SST model yields a stalled solution at an angle-of-attack of $34^{\circ}$, resulting in a large under-prediction of upper surface pressures and lift. This characteristic of SST solution is vividly seen in Fig. 15 that shows the surface pressure contour plots, surface streamlines, and streamlines in a streamwise plane, derived from SA and SST fine grid solutions. The SA solution indicates attached flow over most of the upper surface, whereas the SST solution indicates a large region of separated flow on the main wing and in the streamwise plane.

Figure 16 examines the spanwise surface pressures at one station (flapfwdspan) on the flap. The figure compares SA and SST computed pressures with the measurements at angles-of-attack of $6^{\circ}, 13^{\circ}, 21^{\circ}, 28^{\circ}$, and $34^{\circ}$. Solutions from the SA model are in better agreement with the measured data at this station as well. The SA model at an angleof-attack of $6^{\circ}$ is found to be in excellent agreement all along the span. At other angles-of-attack, the SA solutions generally compare very well inboard of span location $Y=-80$. The region outboard of $Y=-80$ is close to the wing tip, which has been observed to be a challenging region for the computational grids and models applied in the present study. Undulations of the measured pressures are due to interference effects from the slat and flap brackets ${ }^{5}$.

\section{Concluding Remarks}

Results for a generic high-lift NASA Trapezoidal wing configuration obtained using the TetrUSS flow analysis system are presented. The configuration was the focus of the $1^{\text {st }}$ AIAA High-Lift Prediction two-day workshop held in June 2010. Grid convergence and turbulence model sensitivity of the numerical results are examined using the SA and SST turbulence models. Computed longitudinal forces and moment as well as surface pressures are compared with corresponding wind tunnel measurements.

Lift and drag values from the SA model compare quite well with the measured data up to maximum lift condition. However, pitching moment absolute values from the SA model are somewhat lower than the measured values. SST solutions show lower values of lift, drag, and pitching moment (absolute values) as compared to the measured data, specifically at angles-of-attack lower than $28^{\circ}$. The SST model predicts the onset of stalled flow at a lower angle-of-attack than the SA model and wind tunnel measurements.

It is observed that the accuracy of the computed surface pressure degrades closer to the wing tip region. Surface pressures at $98 \%$ span are substantially under-predicted over most of the main wing and entire flap sections. This trend is common to both turbulence models. It is surmised that a much finer grid in the wing tip region may improve the accuracy by better resolving the wing tip vortex.

\section{Acknowledgments}

The first two authors would like to acknowledge the NASA Subsonic Fixed Wing Project for funding support of this effort.

\section{References}

${ }^{1}$ Slotnick, J. P., Hannon, J. A., and Chaffin, M., "Overview of the First AIAA CFD High Lift Prediction Workshop (Invited)," AIAA Paper 2011-862.

${ }^{2}$ Johnson, P. L., Jones, K. M., and Madson, M. D., "Experimental Investigation of a Simplified 3D High Lift Configuration in Support of CFD Validation," AIAA-2000-4217.

${ }^{3}$ McGinley, C. B., Jenkins, L. N., Watson, R. D., and Bertelrud, A,"3-D High-Lift Flow Physics Experiment - Transition Measurements," AIAA paper 2005-5148.

${ }^{4}$ Chaffin, M. S. and Pirzadeh, S., "Unstructured Navier-Stokes High-Lift Computations on a Trapezoidal Wing," AIAA Paper 2005-5084.

${ }^{5}$ Rumsey, C. L., Long, M., Stuever, R. A., and Wayman, T. R., "Summary of the First AIAA CFD High Lift Prediction Workshop", AIAA Paper 2011-939.

${ }^{6}$ Frink, N. T., Pirzadeh, S. Z., Parikh, P. C., Pandya, M. J., and Bhat, M. K., "The NASA tetrahedral unstructured software system (TetrUSS)," The Aeronautical Journal, Vol. 104, No. 1040, 2000, pp. 491-499.

${ }^{7}$ Pandya, M. J., Frink, N. T., Abdol-Hamid, K. S., Samareh, J. A., and Taft, J. R., "Enhancements to TetrUSS for NASA Constellation Program," AIAA Paper 2011-1111.

${ }^{8}$ Reyes, D. A., Girimaji, S. S., Pandya, M. J., and Abdol-Hamid, K. S., "Computations of High-Lift Wing-Body Configuration on Unstructured Grids using k- $\omega$ models," AIAA Paper 2011-868.

${ }^{9}$ Campbell, R. L., "Efficient Viscous Design of Realistic Aircraft Configuration (Invited)," AIAA Paper 1998-2539.

${ }^{10}$ Lohner, R. and Parikh, P., "Three-dimensional grid generation by the advancing front method," International Journal for Numerical Methods in Fluids," Vol. 8, Issue 10, 1988, pp. 1135-1149.

${ }^{11}$ Pirzadeh, S. Z., "Three-dimensional unstructured viscous grids by the advancing layer method," AIAA Journal, Vol. 33, No. 1, 1996, pp. 43-49. 
${ }^{12}$ Pirzadeh, S. Z., "Advanced unstructured grid generation for complex aerodynamic applications," AIAA Journal, Vol. 48, No. 5, 2010, pp. 904-915.

${ }^{13}$ Samareh, J., "GridTool: A Surface Modeling and Grid Generation Tool," Proceedings of the Workshop on Surface Modeling, Grid Generation, and Related Issues in CFD Solutions, NASA CP-3291, 9-11 May, 1995.

${ }^{14}$ Frink, N. T., "Upwind scheme for solving the Euler equations on unstructured tetrahedral meshes," AIAA Journal, Vol. 30, No. 1, 1992, pp. 70-77.

${ }^{15}$ Frink, N. T., "Tetrahedral unstructured Navier-Stokes method for turbulent flows," AIAA Journal, Vol. 36, No. 11, 1998, pp. 1975-1982.

${ }^{16}$ Pandya, M.J., Frink, N.T., Abdol-Hamid, K.S., and Chung, J.J., "Recent enhancements to USM3D unstructured flow solver for unsteady flows," AIAA Paper 2004-5201, August 16-19 2004.

${ }^{17}$ Frink, N.T., Bonhaus, D.L., Vatsa, V.N., Bauer, S.X.S., Tinetti, A.F., “A Boundary Condition for Simulation of Flow Over Porous Surfaces," Journal of Aircraft, Vol. 40, No. 4, July-August 2003, pp. 692-698.

${ }^{18}$ Spalart P., and Allmaras S. A., "One-Equation Turbulence Model for Aerodynamic Flows," AIAA Paper 92-0439, January 1992.

${ }^{19}$ Menter, F.R., "Improved Two-Equation k-omega Turbulence Models for Aerodynamic Flows," NASA TM-103975, October 1992.

${ }^{20}$ Abdol-Hamid, K. S., Frink, N. T., Deere, K. A., and Pandya, M. J., "Propulsion Simulations Using Advanced Turbulence Models with the Unstructured-Grid CFD Tool, TetrUSS," AIAA Paper 2004-0714, January 2004.

${ }^{21}$ Pandya, M.J., Frink, N.T., and Noack, R.W., "Overset-grid moving body capability in the USM3D unstructured flow solver," AIAA Paper 2005-5118. 


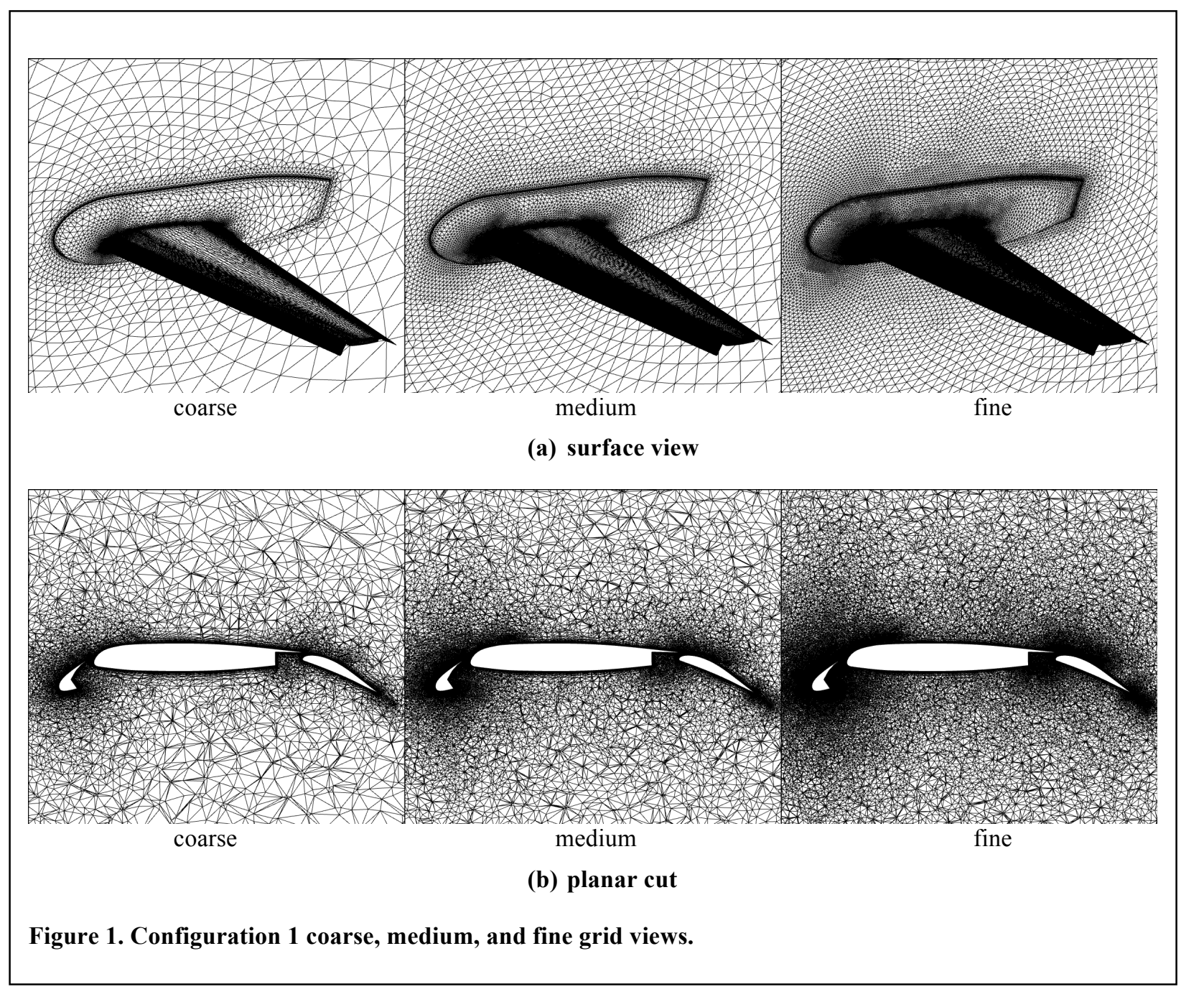



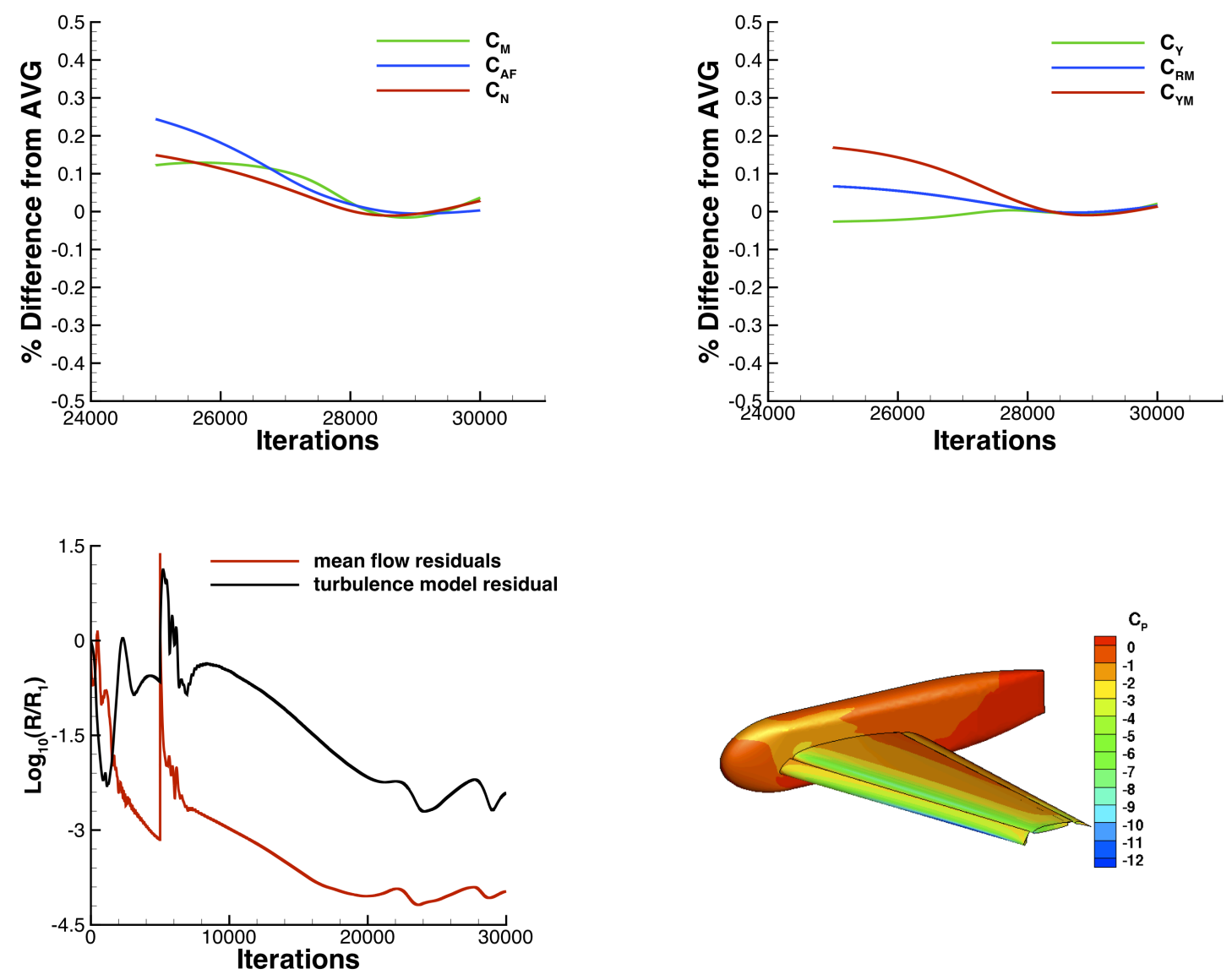

Figure 2. Representative plot of USM3D solution convergence for Configuration 1 (angle-of-attack $28^{\circ}$, SA model).

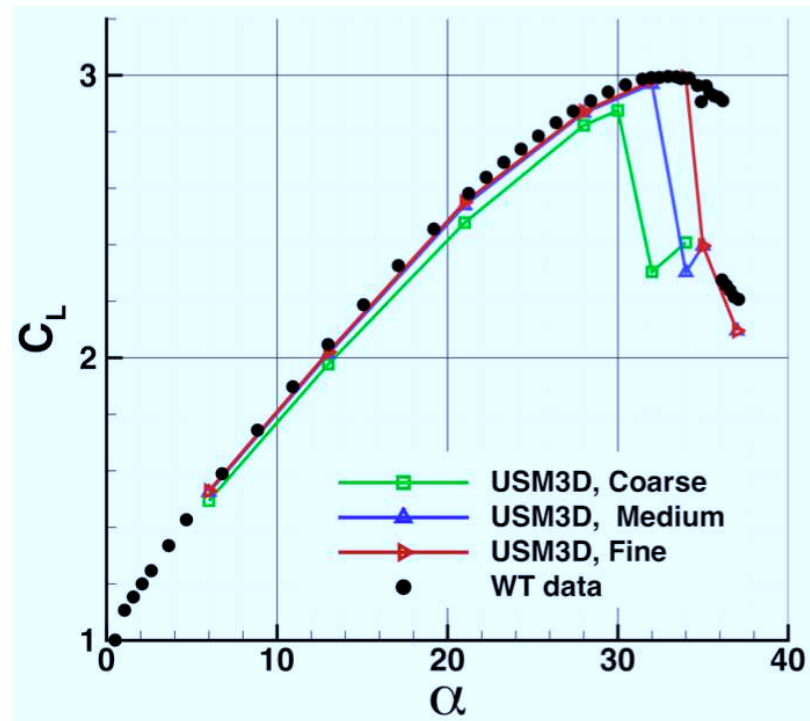

(a) SA model

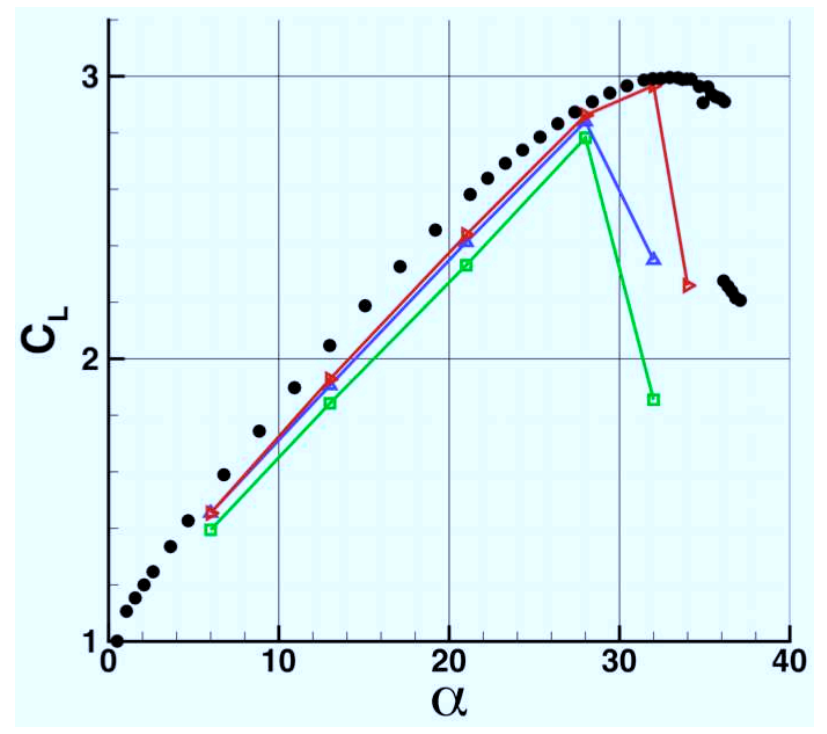

(b) SST model

Figure 3. Comparison of computed and measured lift coefficient variations with respect to angle-of-attack. 


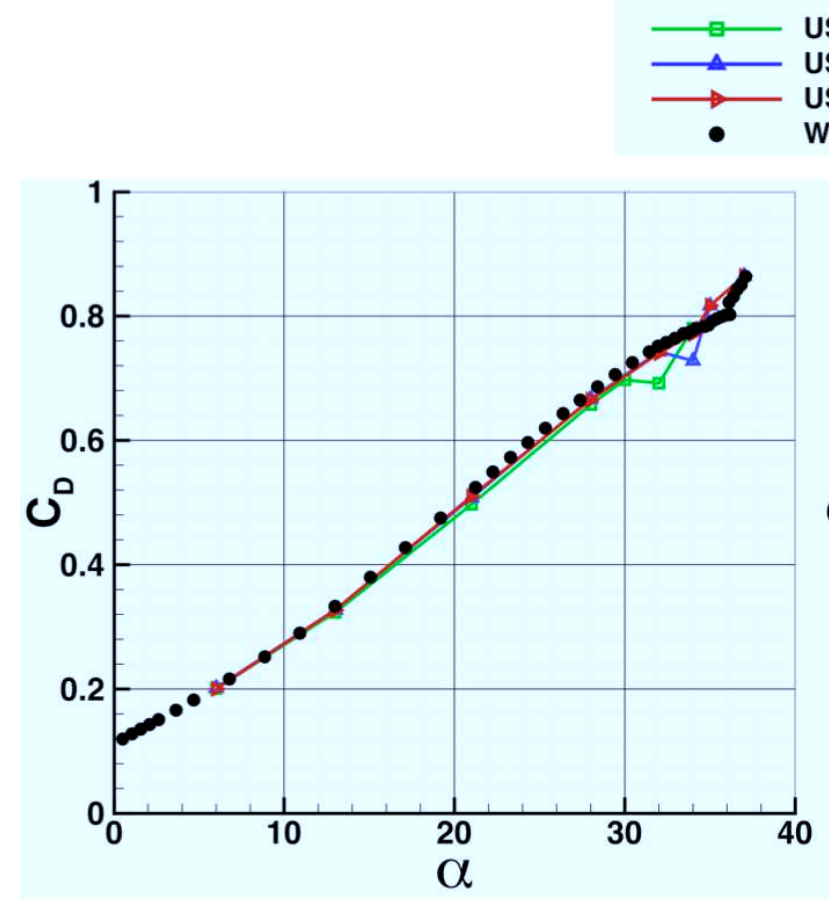

(a) SA model
USM3D, Coarse

USM3D, Medium

USM3D, Fine

WT data

Figure 4. Comparison of computed and measured drag coefficient variations with respect to angle-of-attack.

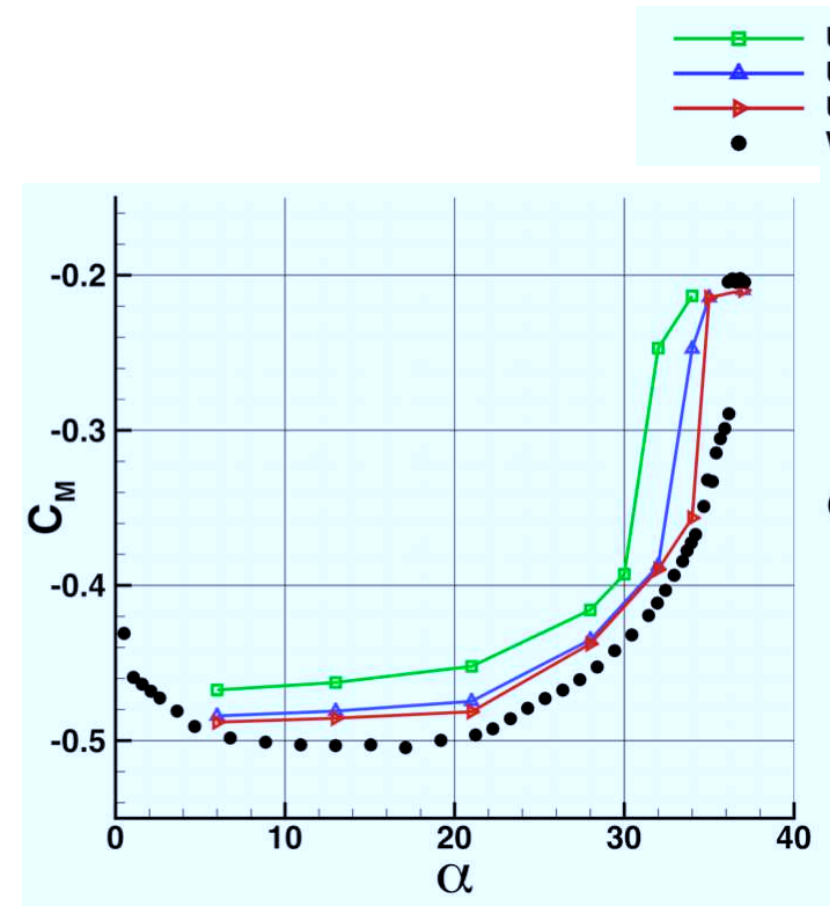

(a) SA model

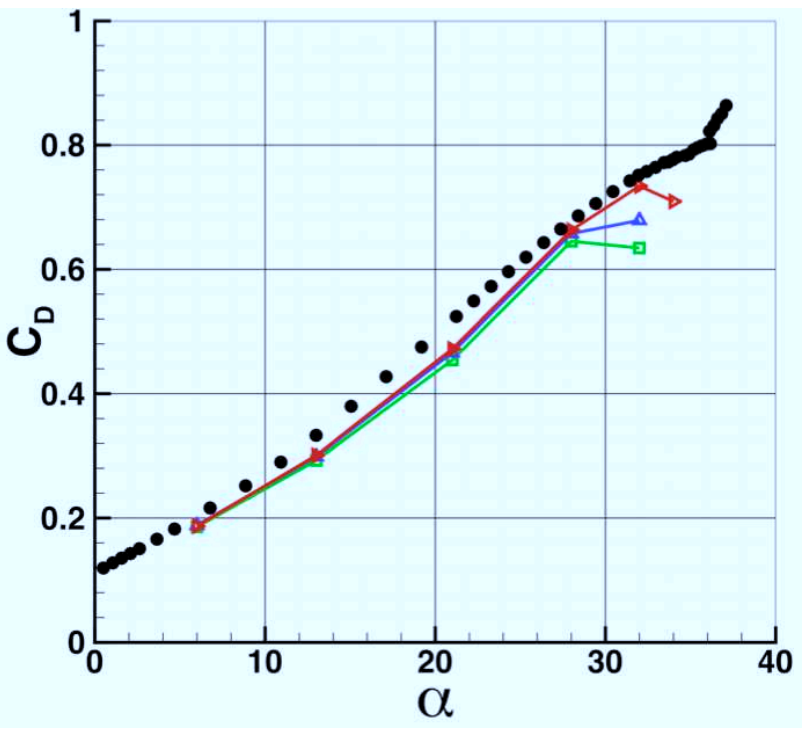

(b) SST model

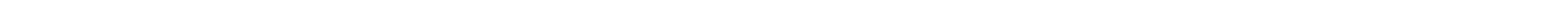
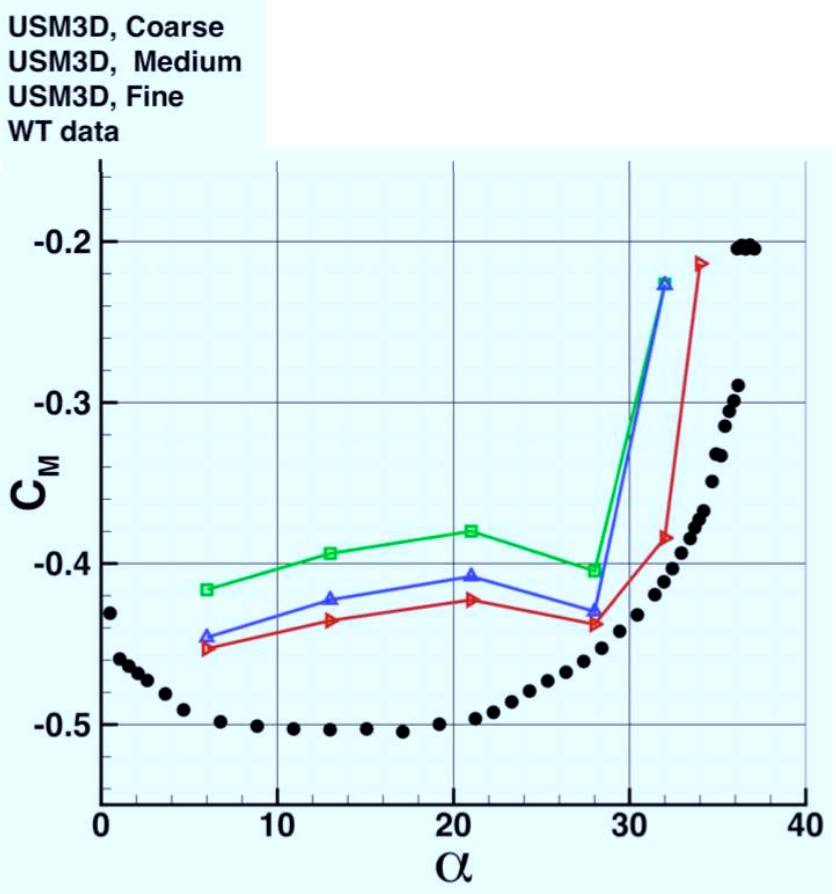

(b) SST model

Figure 5. Comparison of computed and measured pitching moment coefficient variations with respect to angleof-attack. 

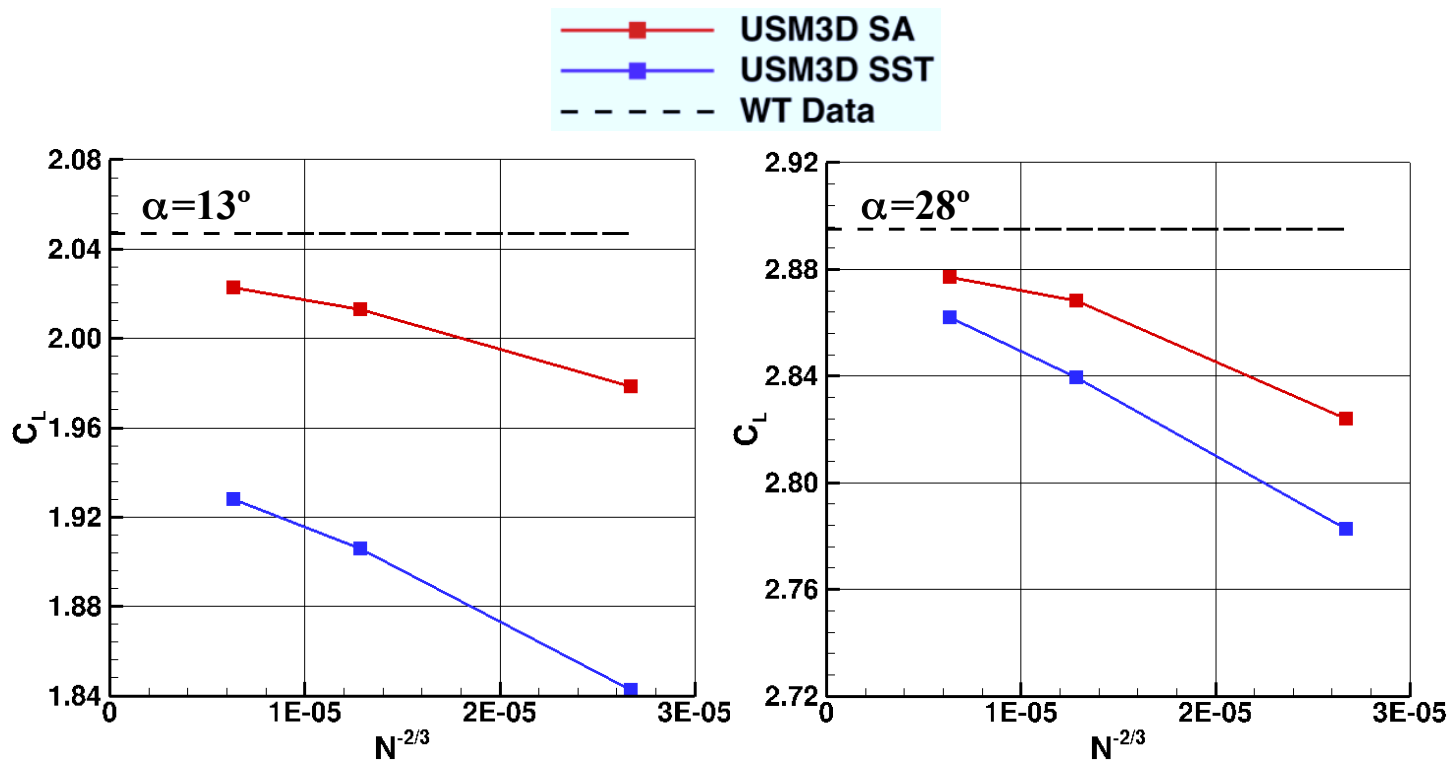

(a) lift coefficient
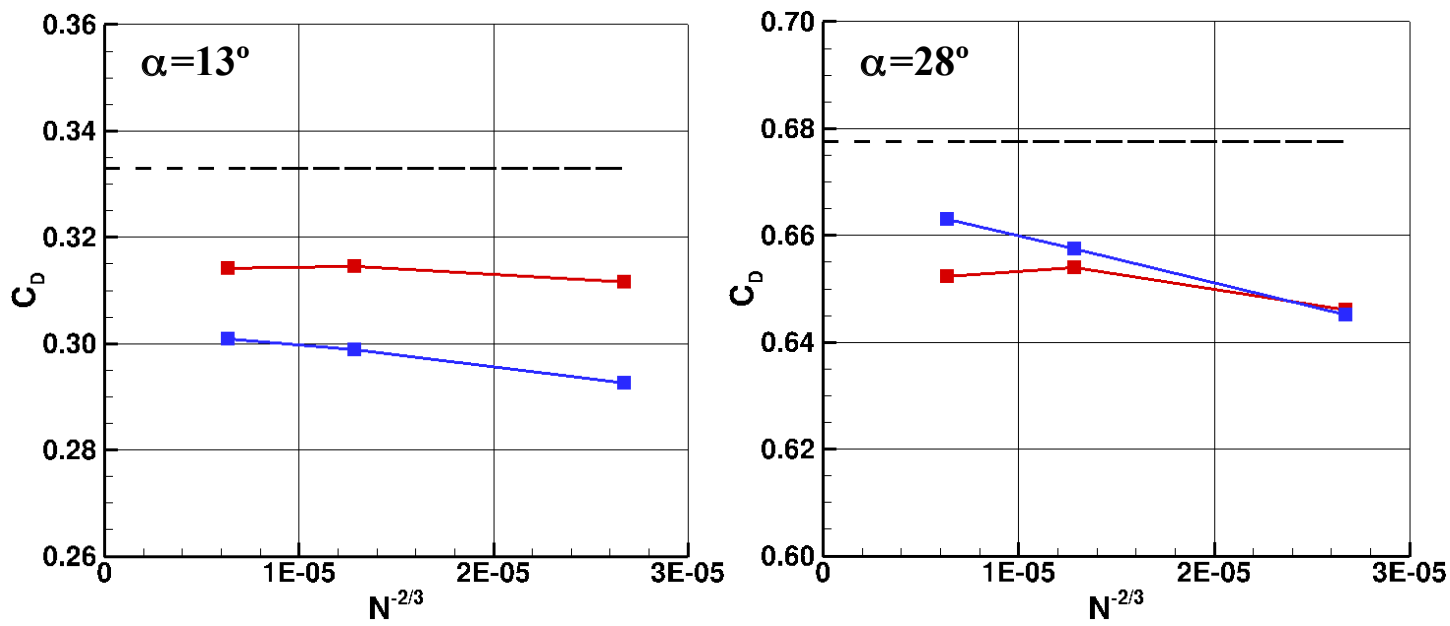

(b) drag coefficient
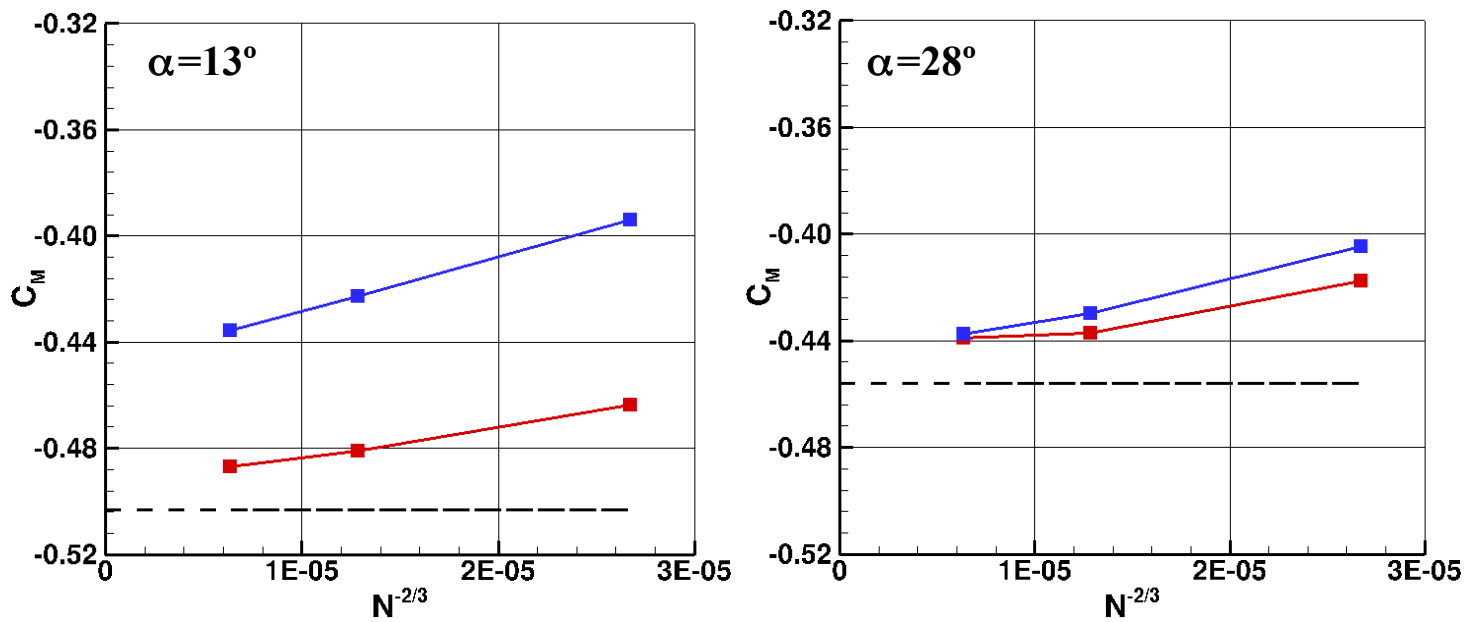

(c) pitching moment coefficient

Figure 6. Grid convergence of longitudinal forces and moment from SA and SST turbulence models.

11

American Institute of Aeronautics and Astronautics 


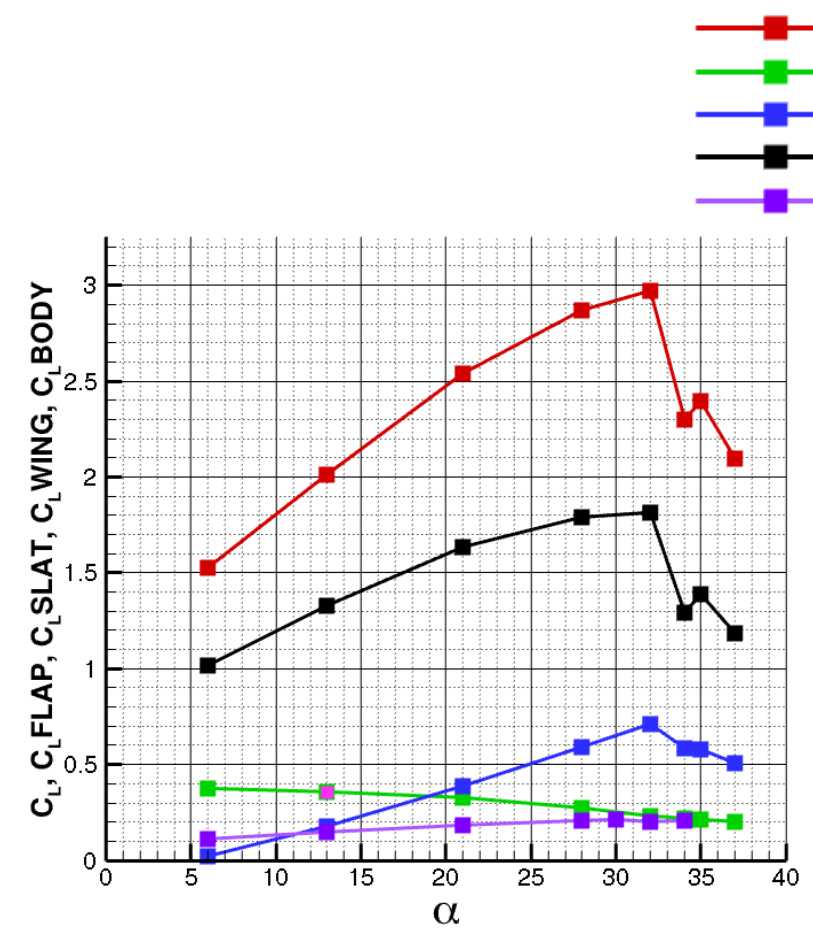

(a) SA model

\section{$\mathbf{C}_{\mathbf{L}}$ CLLAP \\ CSLAT \\ CWING \\ CLODY}

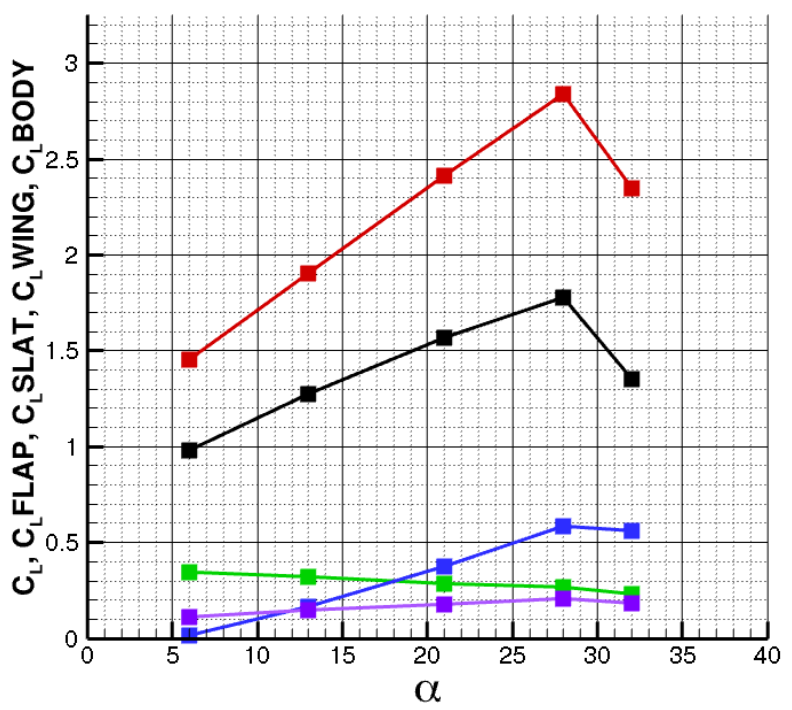

(b) SST model

Figure 7. Lift contribution of main wing, flap, and slat at various angles-of-attack using two turbulence models.

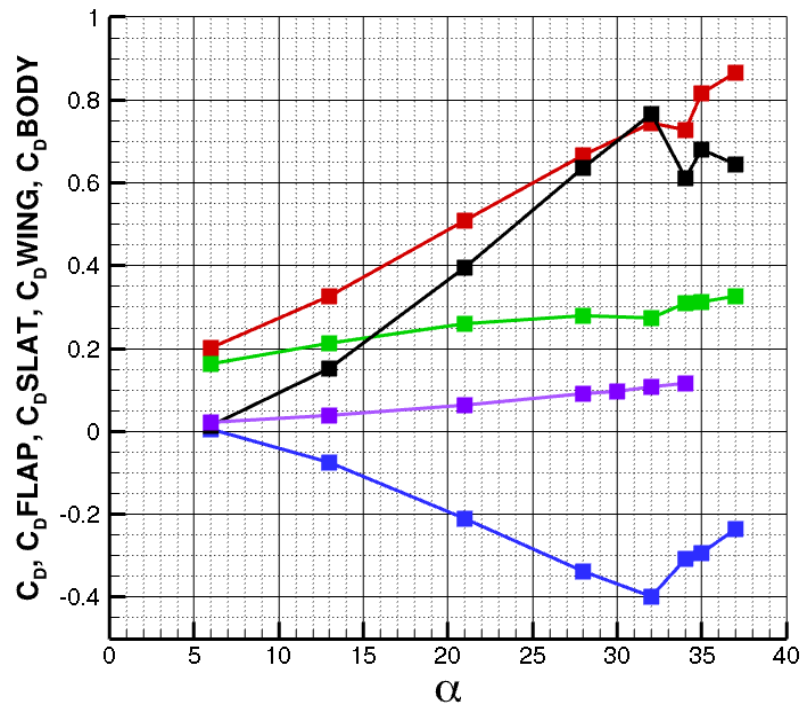

(a) SA model

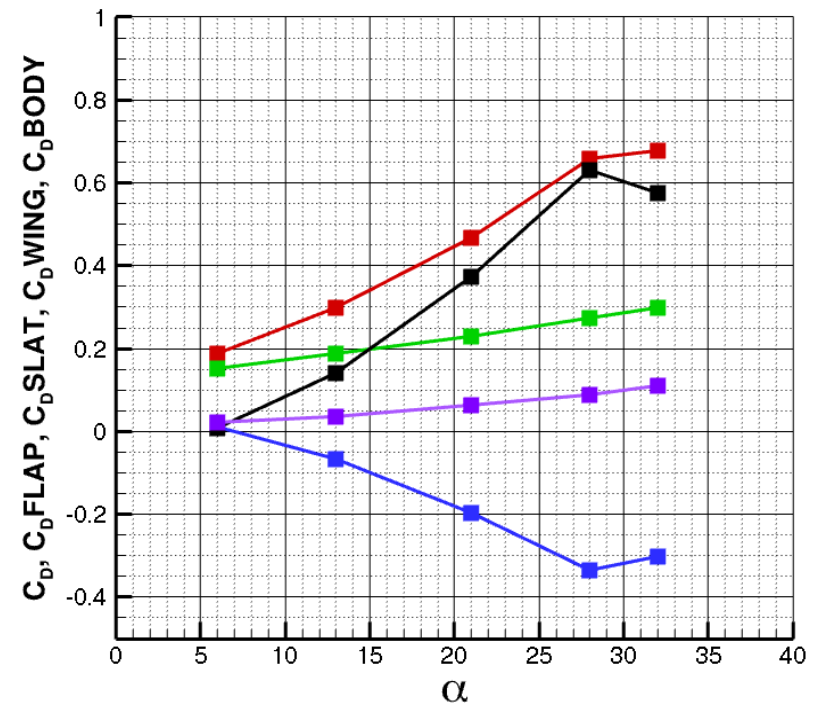

(b) SST model

Figure 8. Drag contribution of main wing, flap, and slat at various angles-of-attack using two turbulence models. 


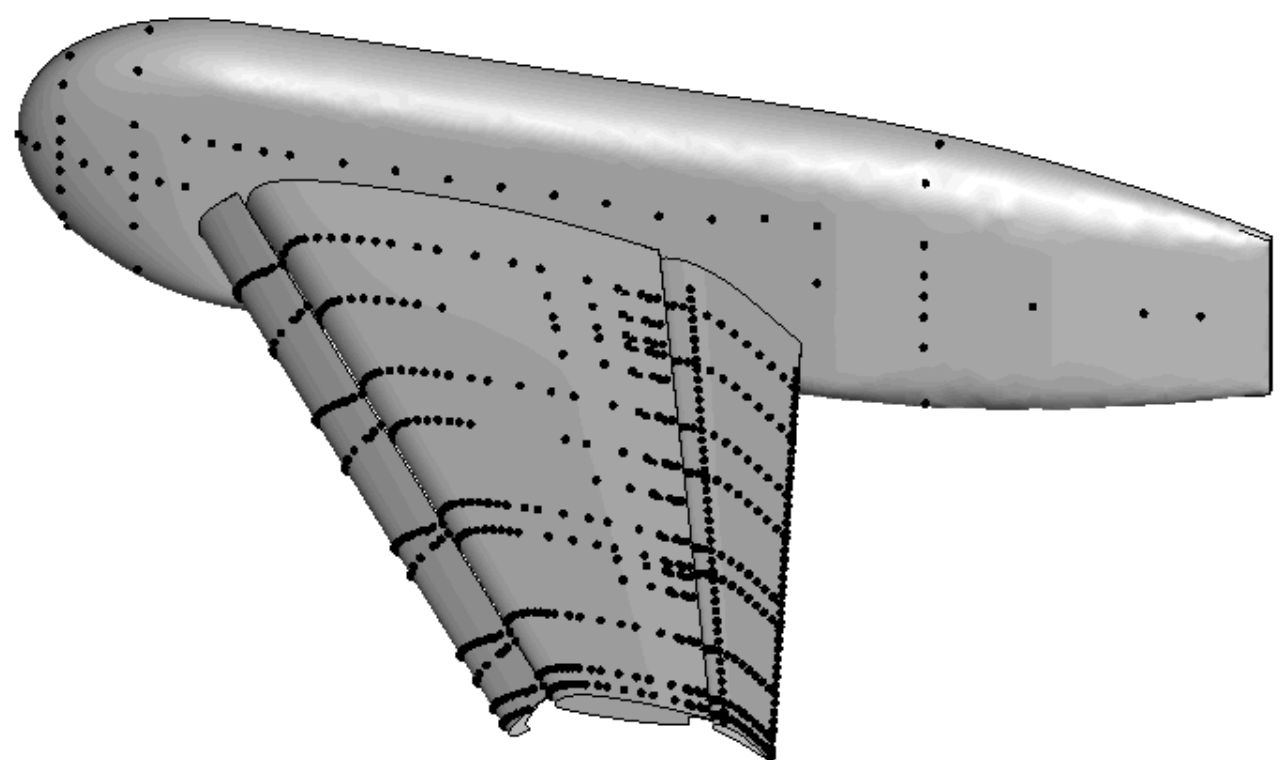

(a) layout of wind tunnel pressure ports

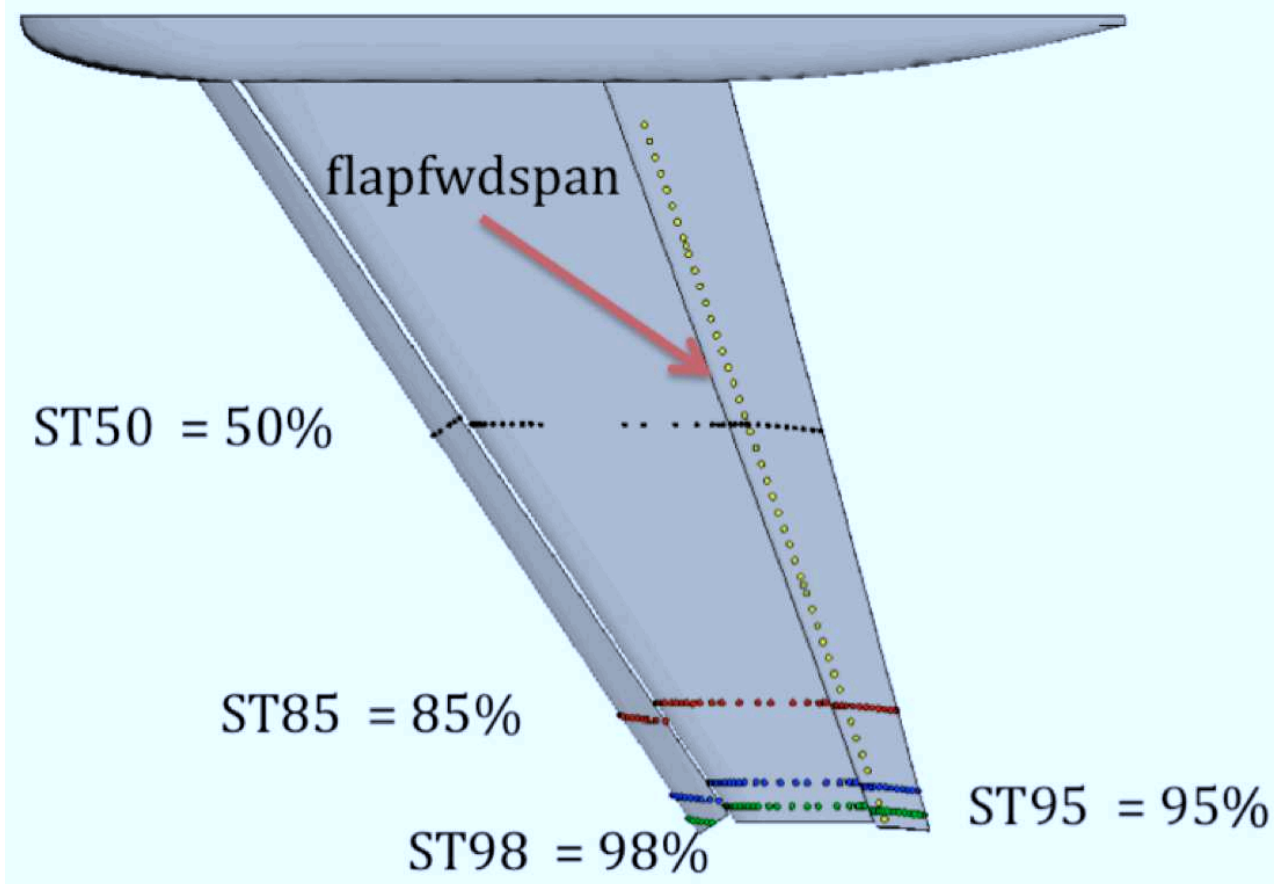

(b) pressure ports used for present analysis

Figure 9. Pressure ports layout for Configuration 1 model. 


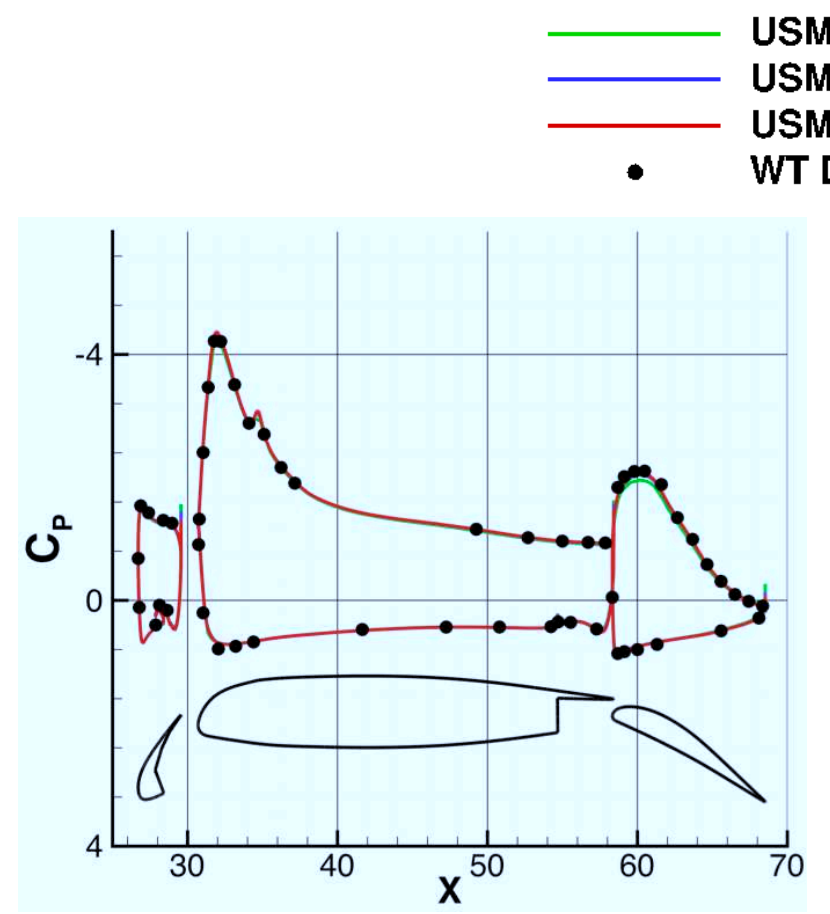

(a) ST50

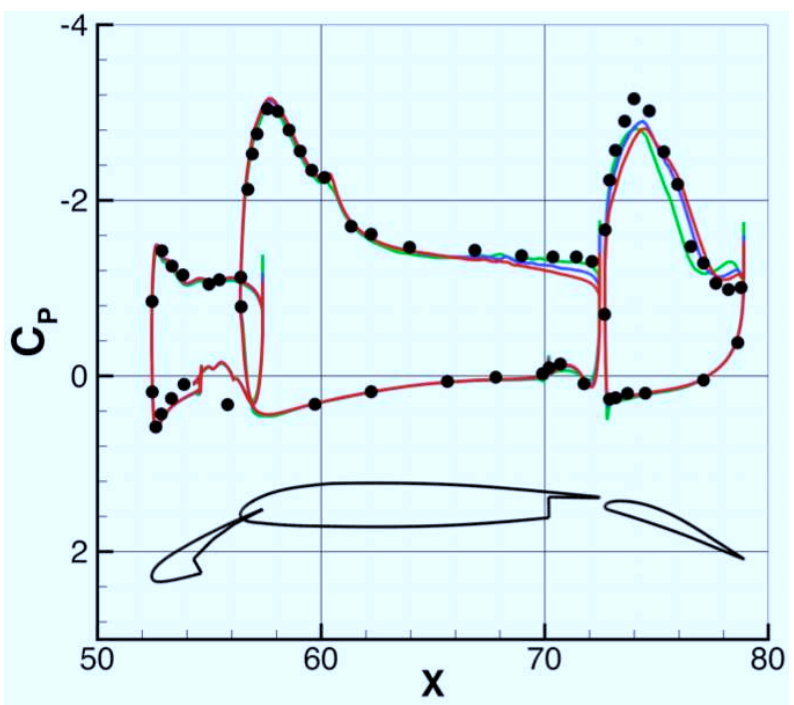

(c) ST95

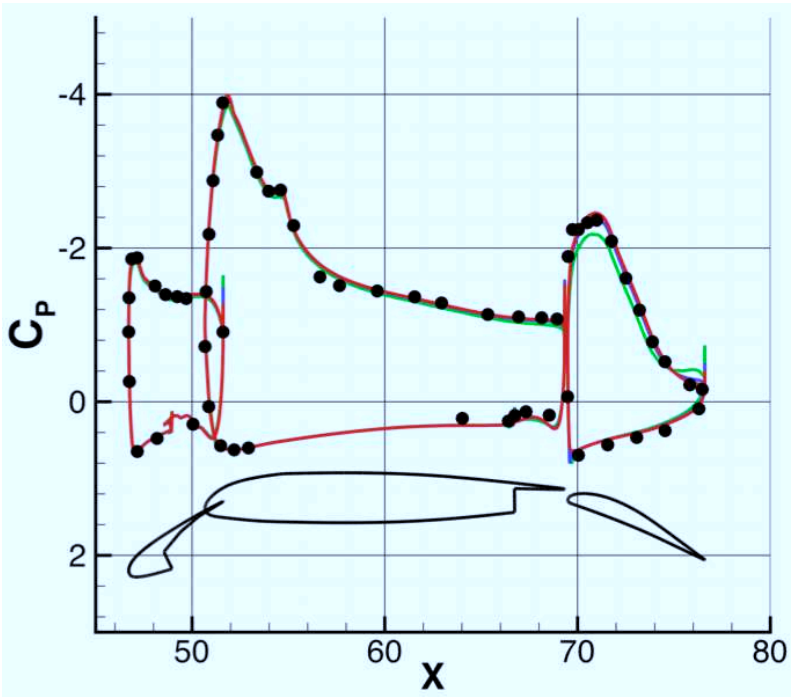

(b) ST85

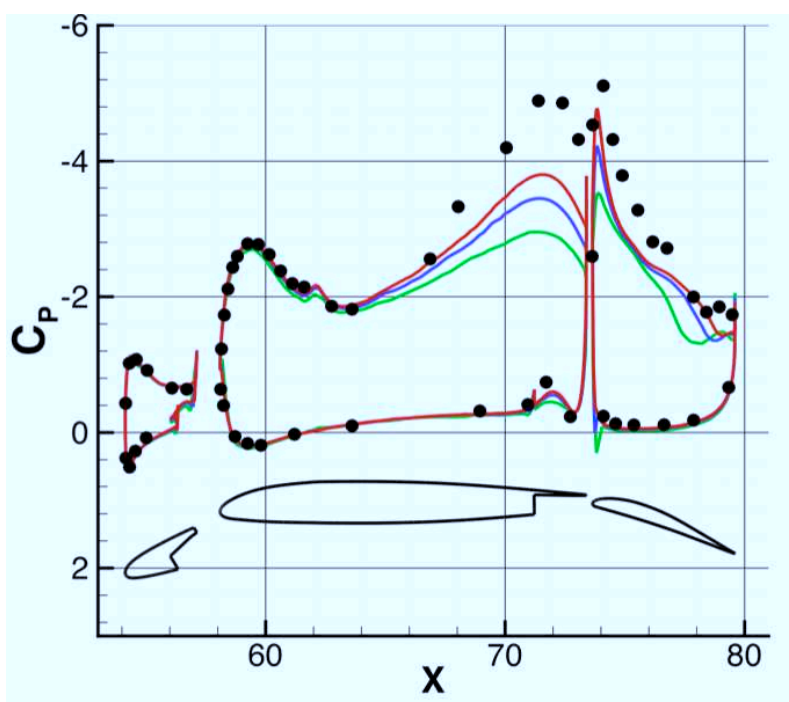

(d) ST98

Figure 10. Comparison of SA model computed and measured surface pressure at four spanwise locations on Configuration 1 at angle-of-attack $13^{\circ}$. 


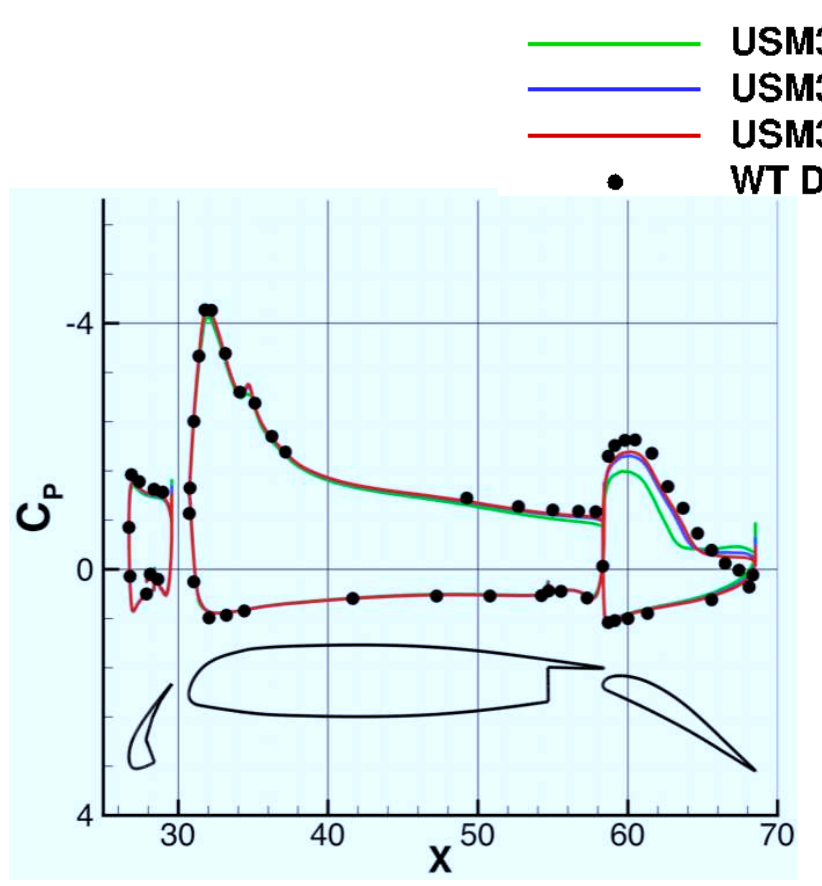

(a) ST50

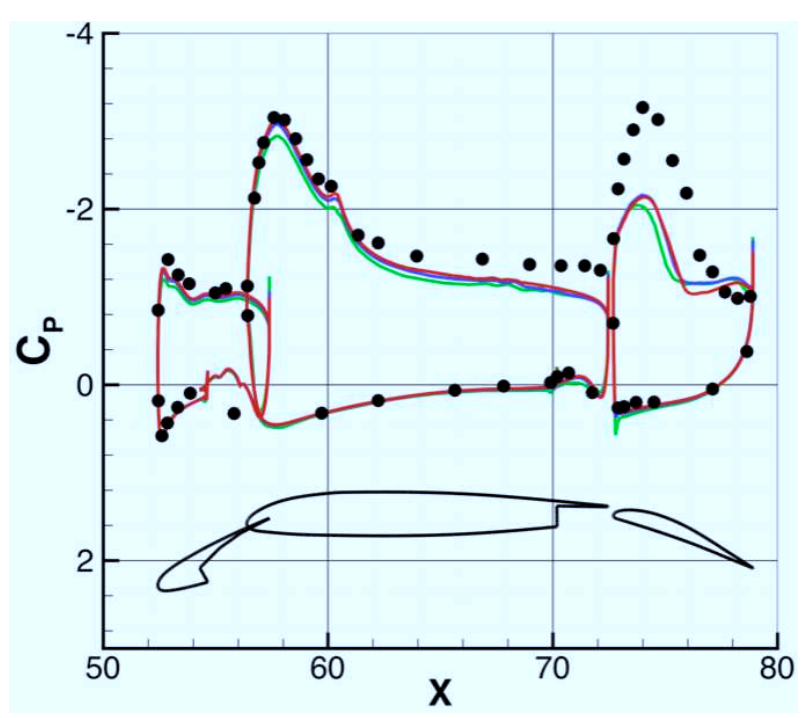

(c) ST95

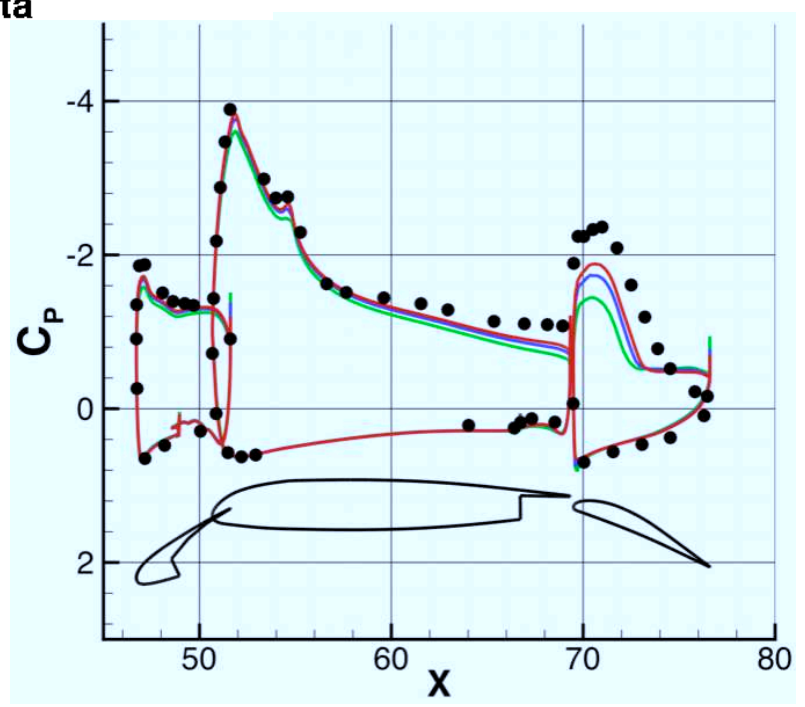

(b) ST85

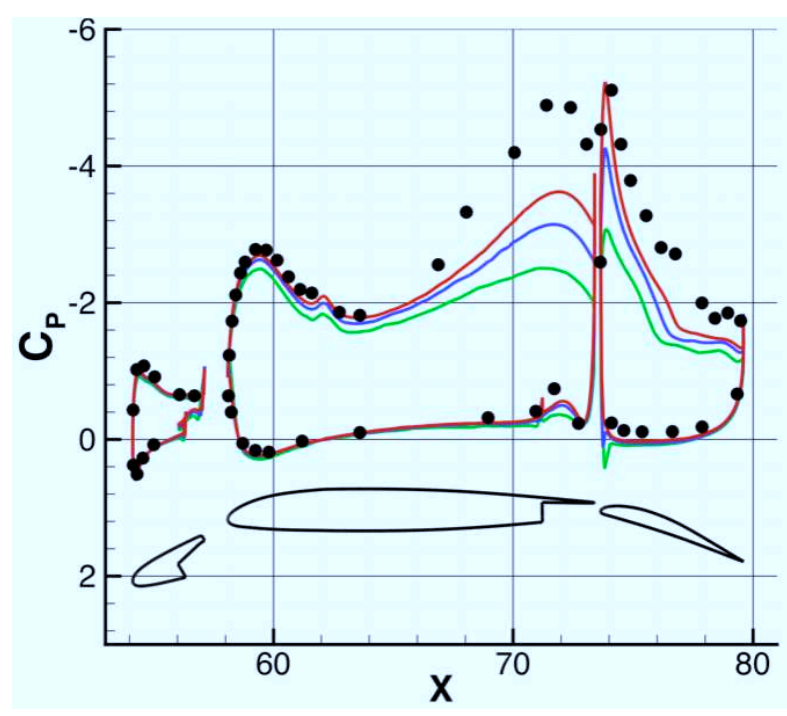

(d) ST98

Figure 11. Comparison of SST model computed and measured surface pressure at four spanwise locations on Configuration 1 at angle-of-attack $13^{\circ}$. 


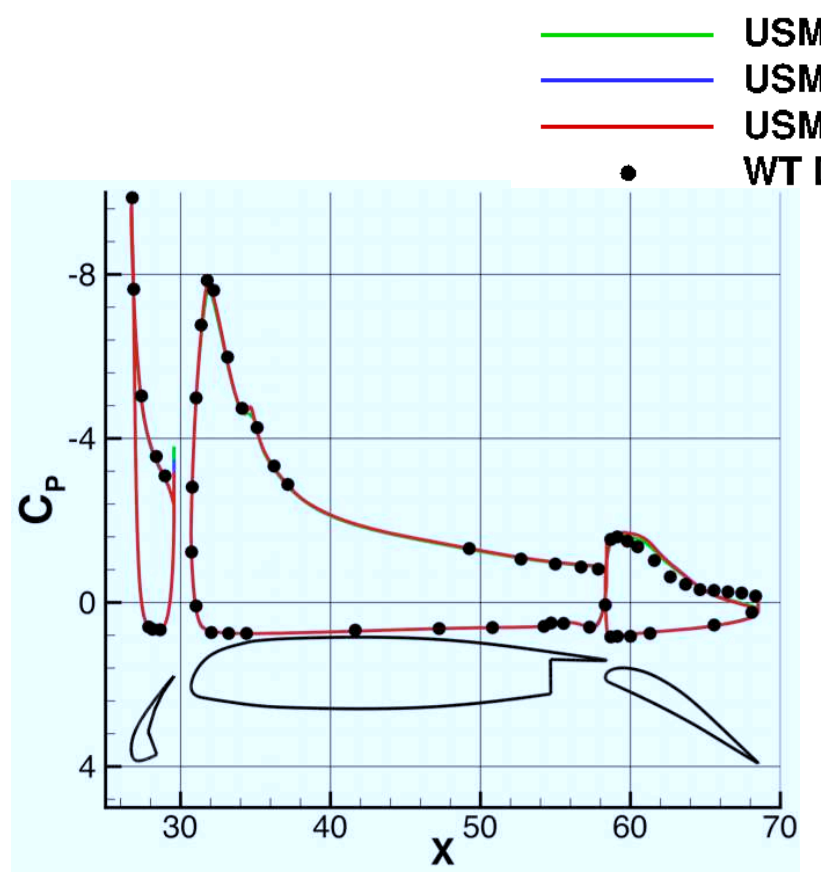

(a) ST50

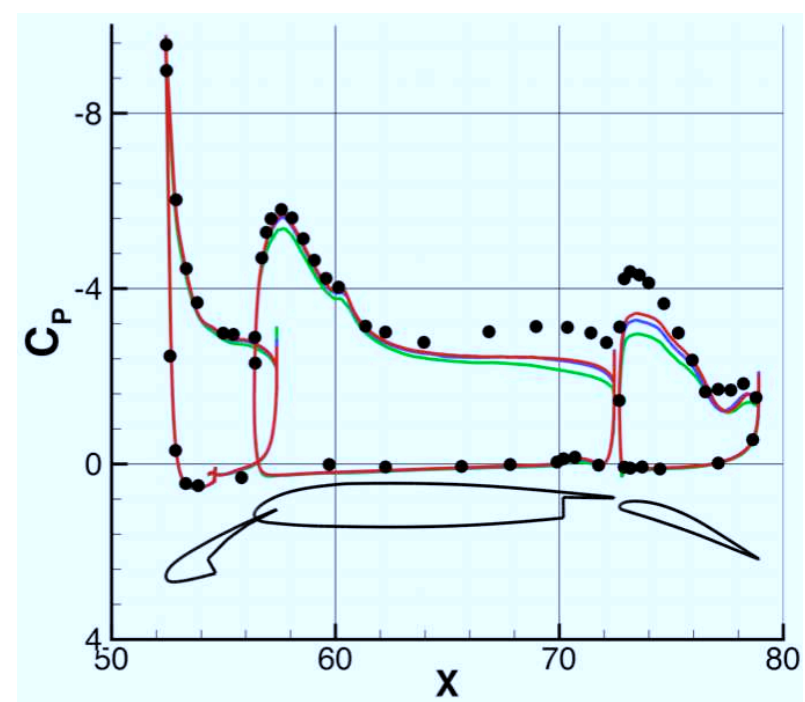

(c) $\mathrm{ST} 95$
USM3D Coarse Grid

USM3D Medium Grid

USM3D Fine Grid

WT Data

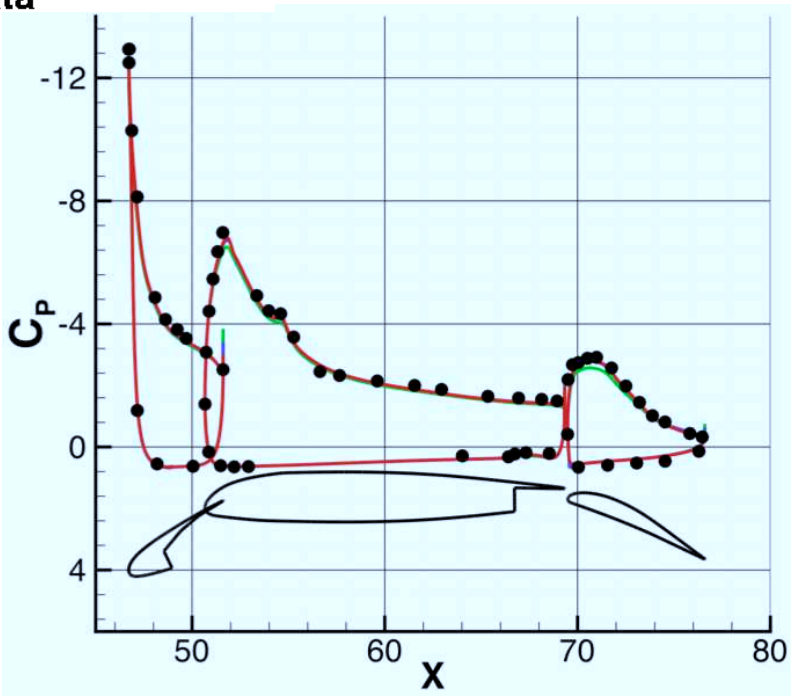

(b) ST85

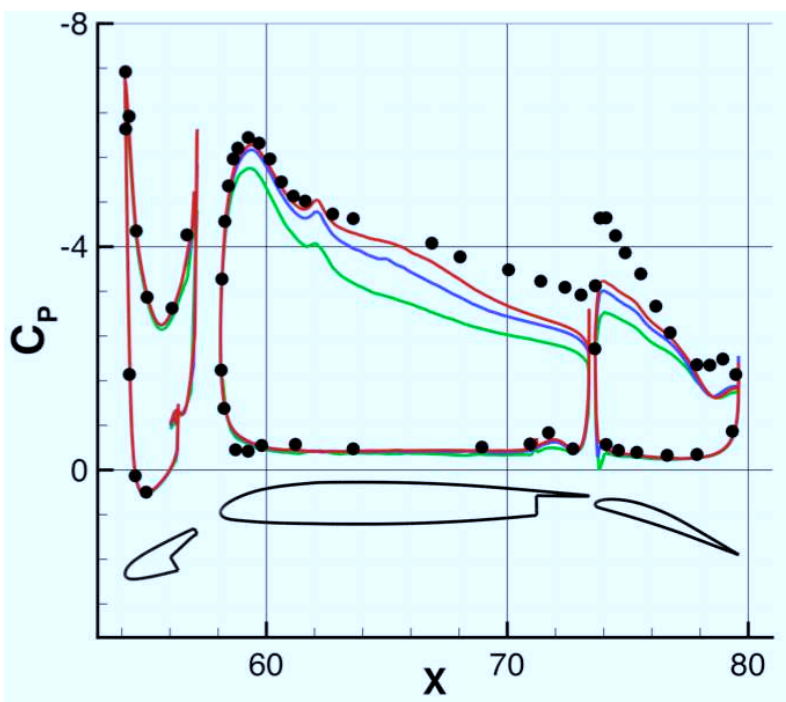

(d) ST98

Figure 12. Comparison of SA model computed and measured surface pressure at four spanwise locations on Configuration 1 at angle-of-attack $28^{\circ}$. 


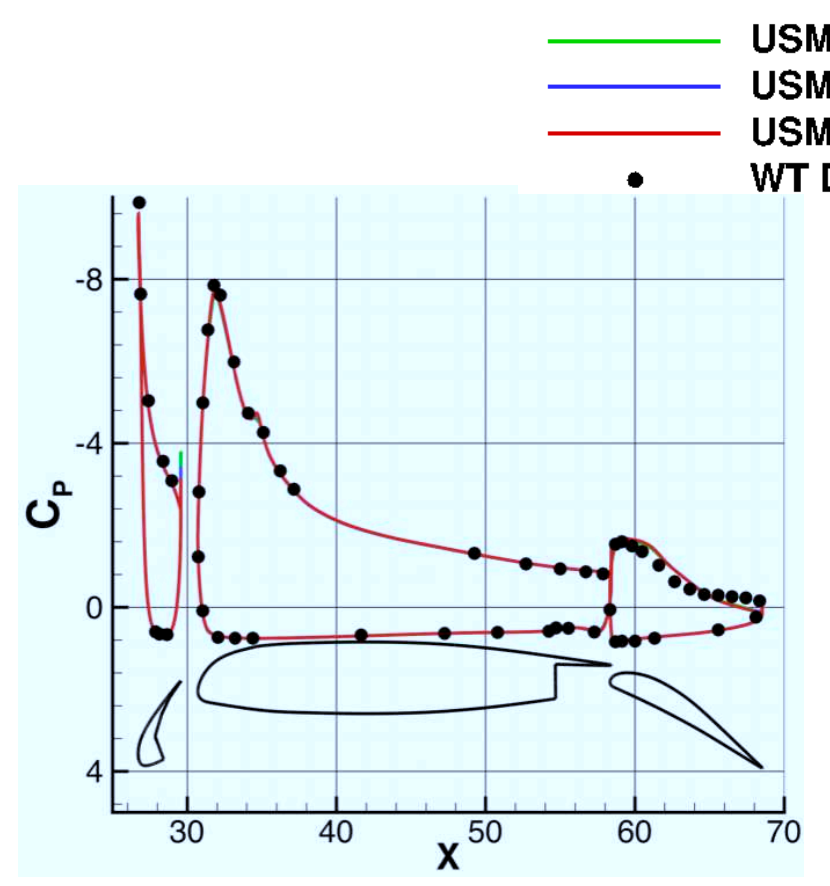

(a) ST50

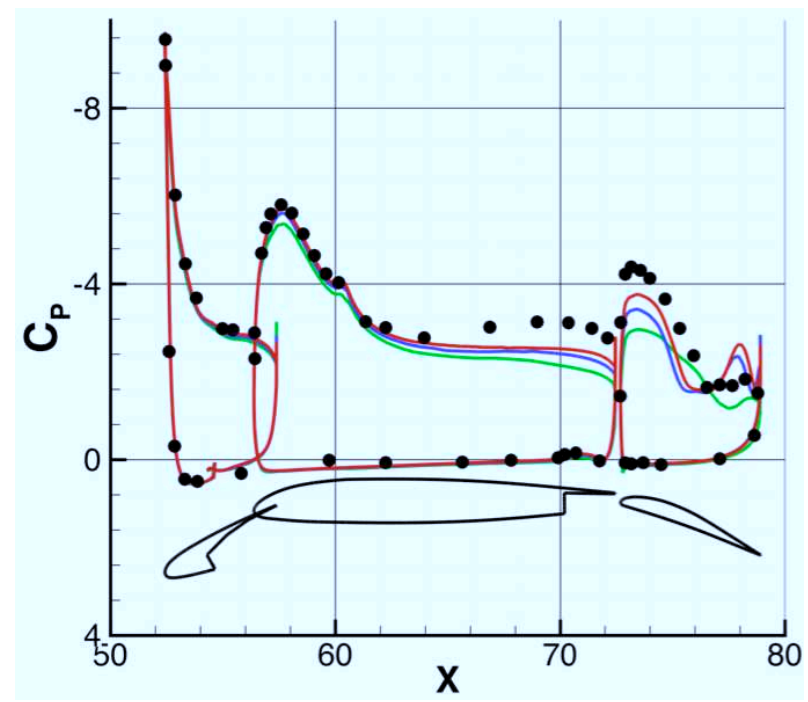

(c) ST95
USM3D Coarse Grid USM3D Medium Grid USM3D Fine Grid WT Data

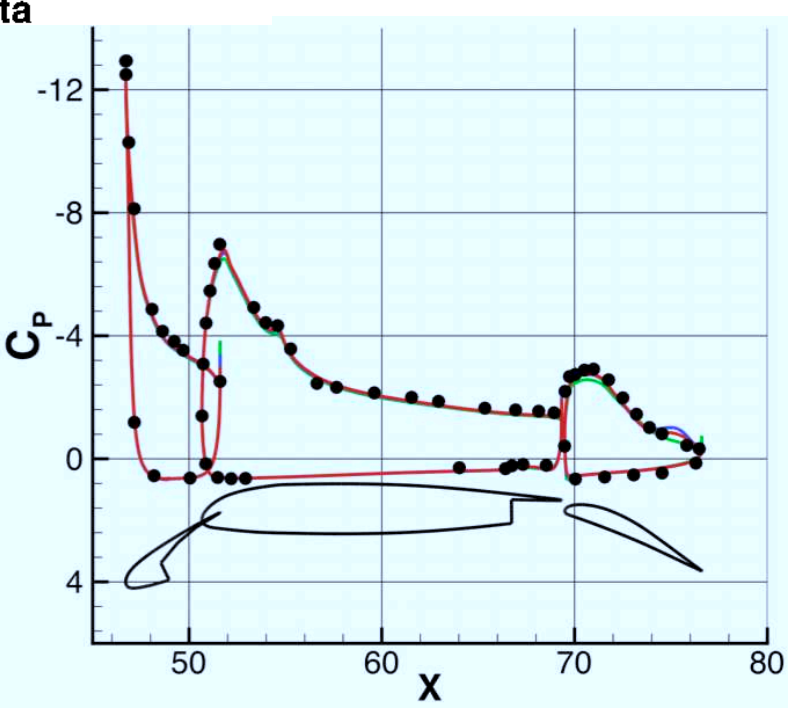

(b) ST85

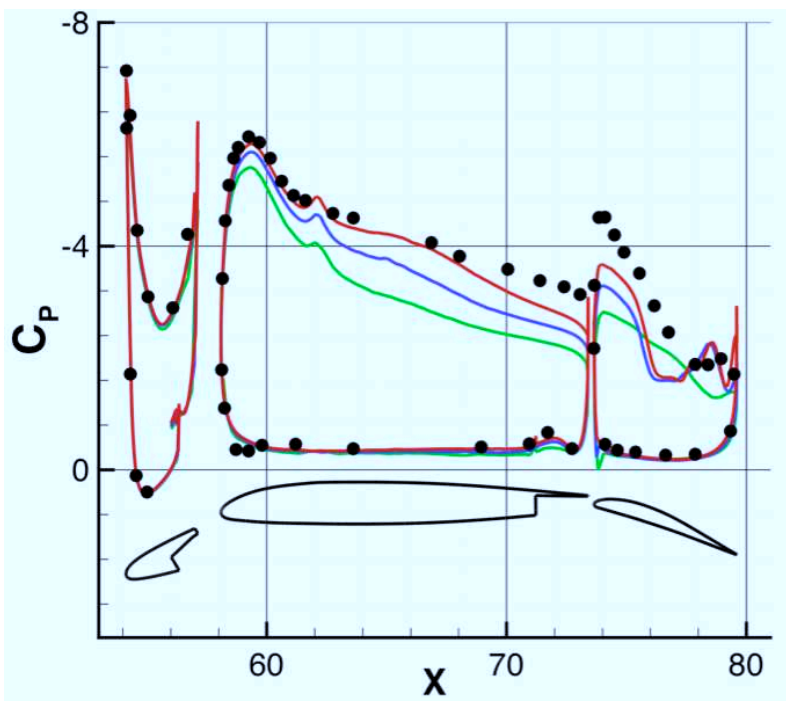

(d) ST98

Figure 13. Comparison of SST model computed and measured surface pressure at four spanwise locations on Configuration 1 at angle-of-attack $28^{\circ}$. 

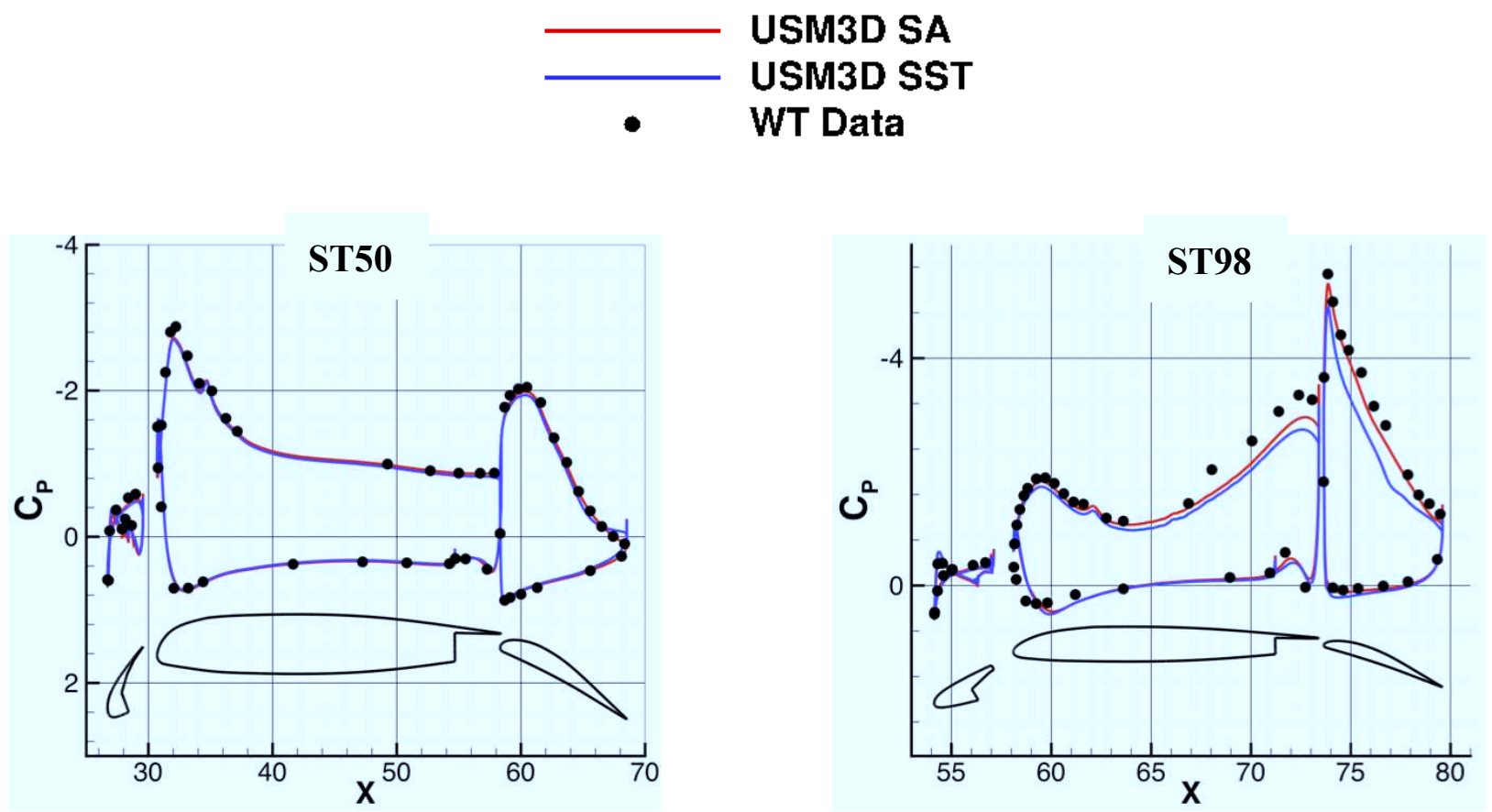

(a) $\alpha=6^{\circ}$
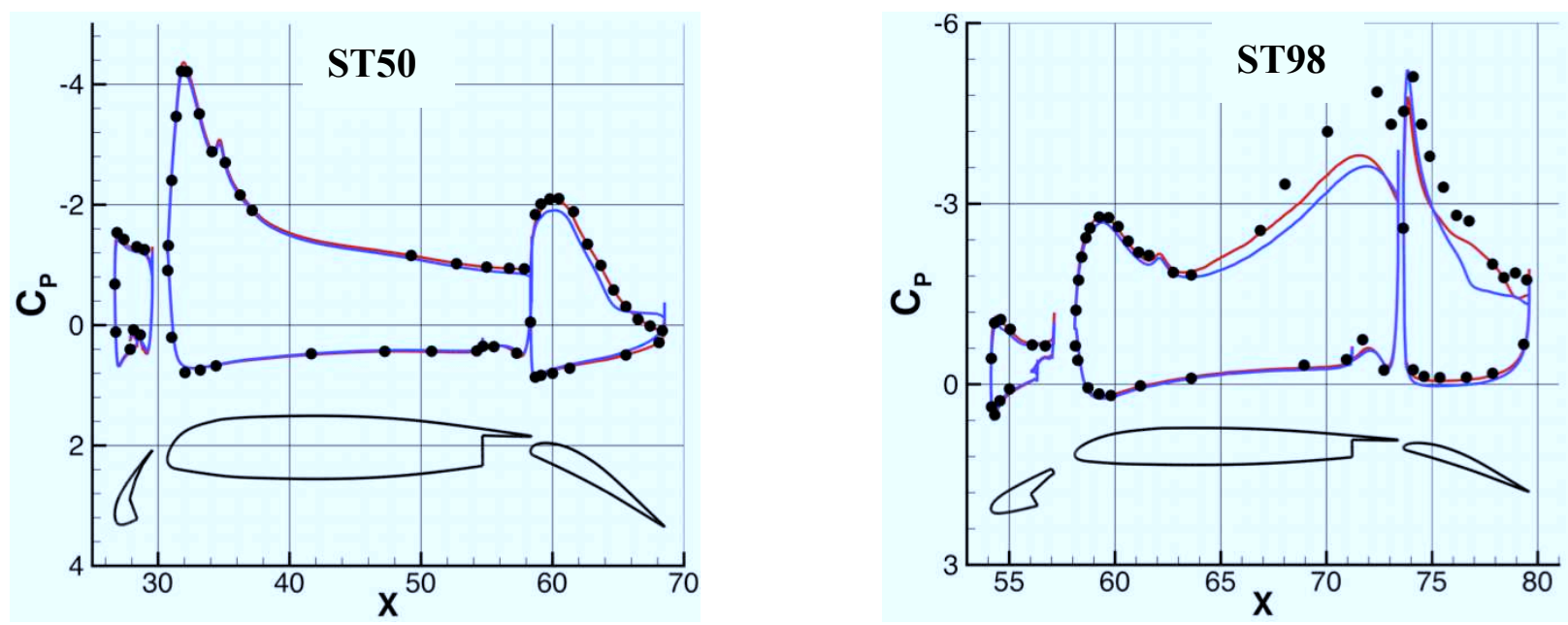

(b) $\alpha=13^{\circ}$

Figure 14. Comparison of fine grid SA and SST model computed and measured surface pressure at two representative spanwise locations on Configuration 1 at various angles-of-attack. 


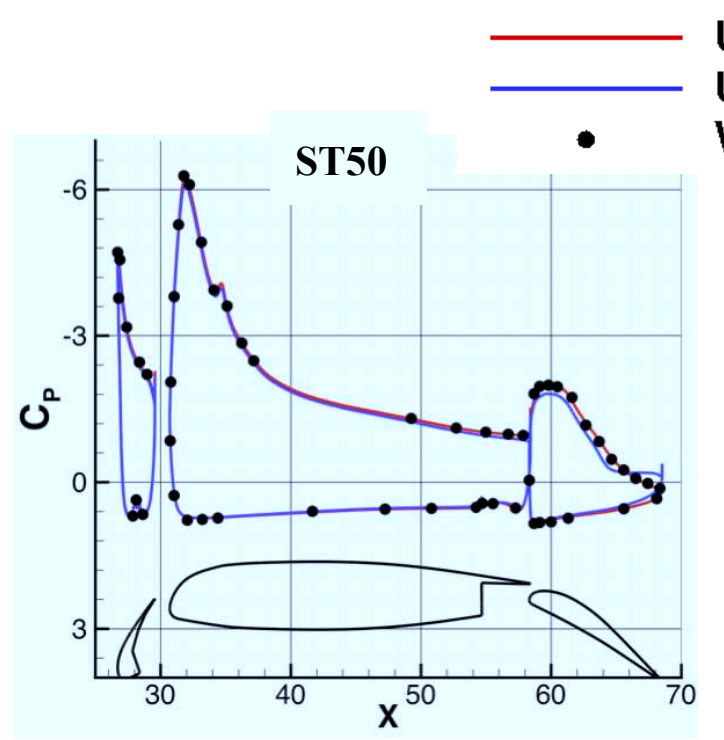

USM3D SA
USM3D SST

WT Data

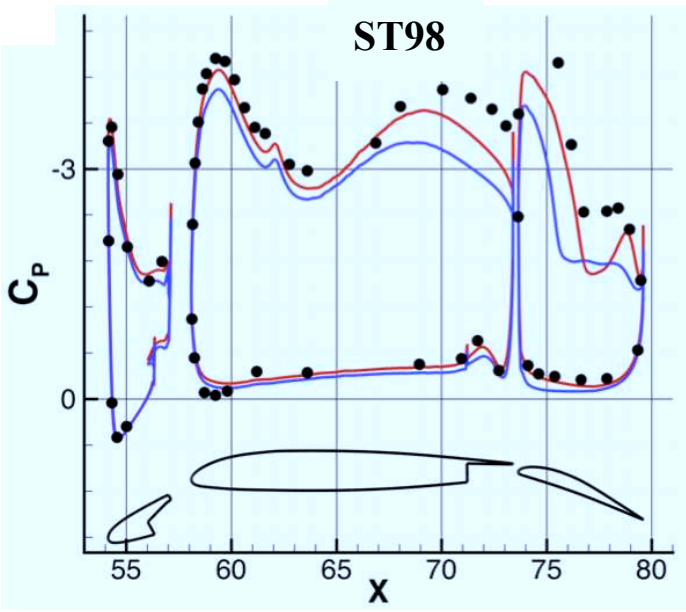

(c) $\alpha=21^{\circ}$
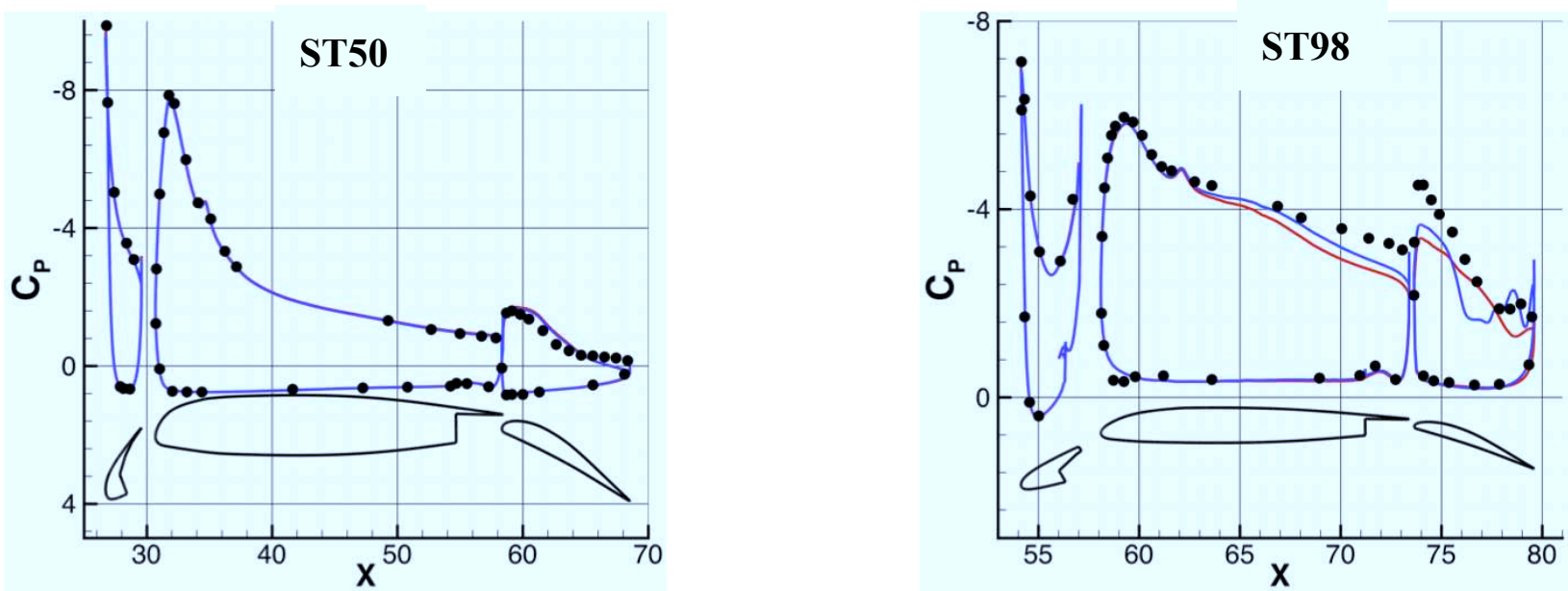

(d) $\alpha=\mathbf{2 8}^{\circ}$
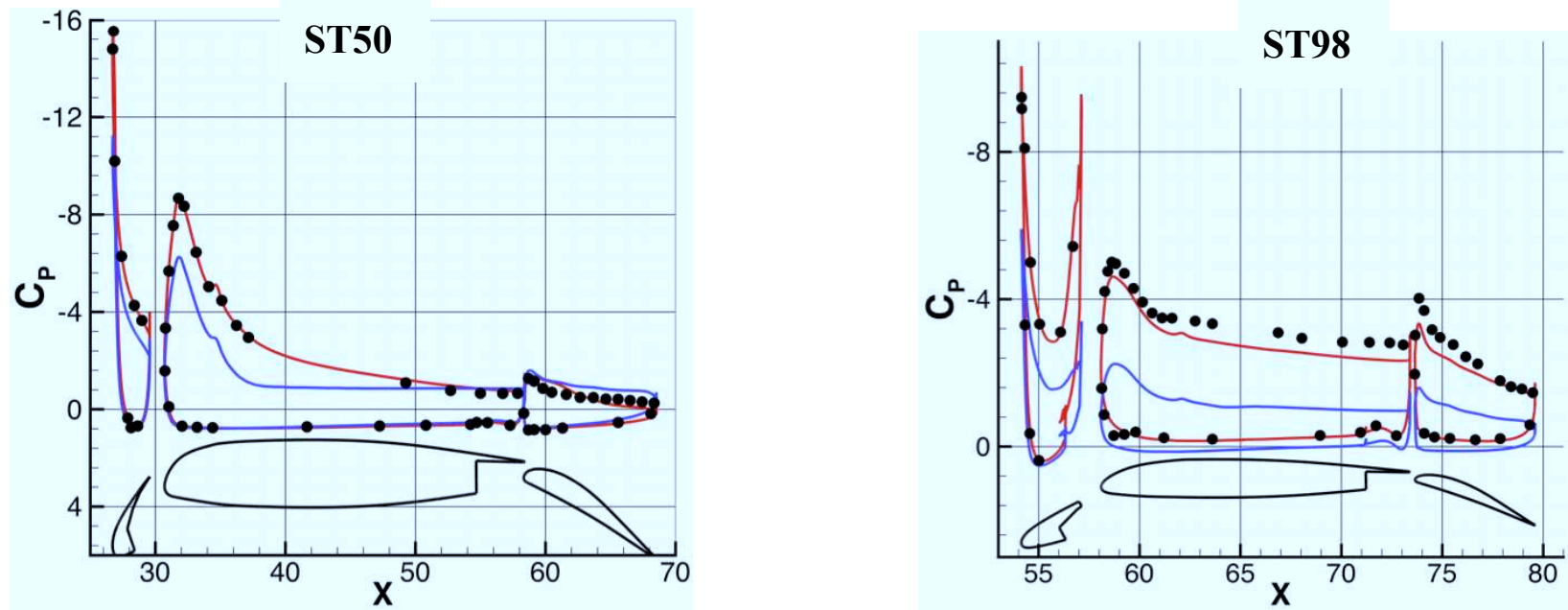

(e) $\alpha=34^{\circ}$

Figure 14. Concluded. 


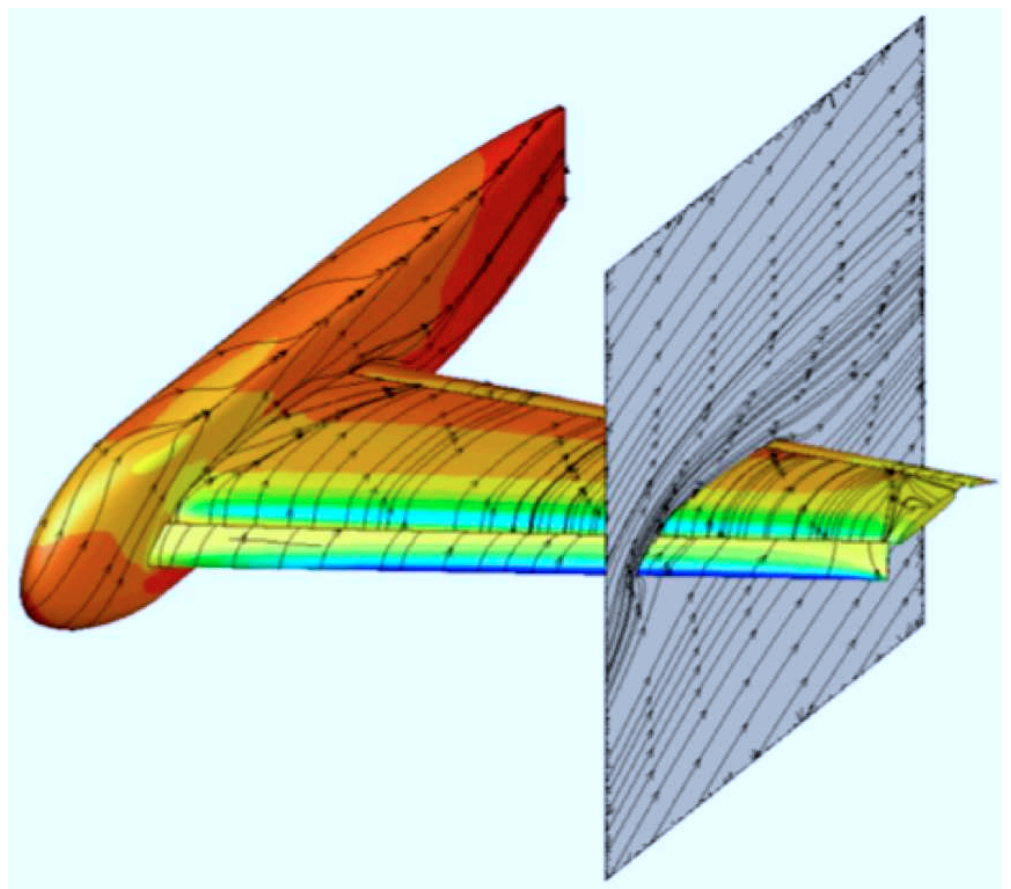

(a) SA model

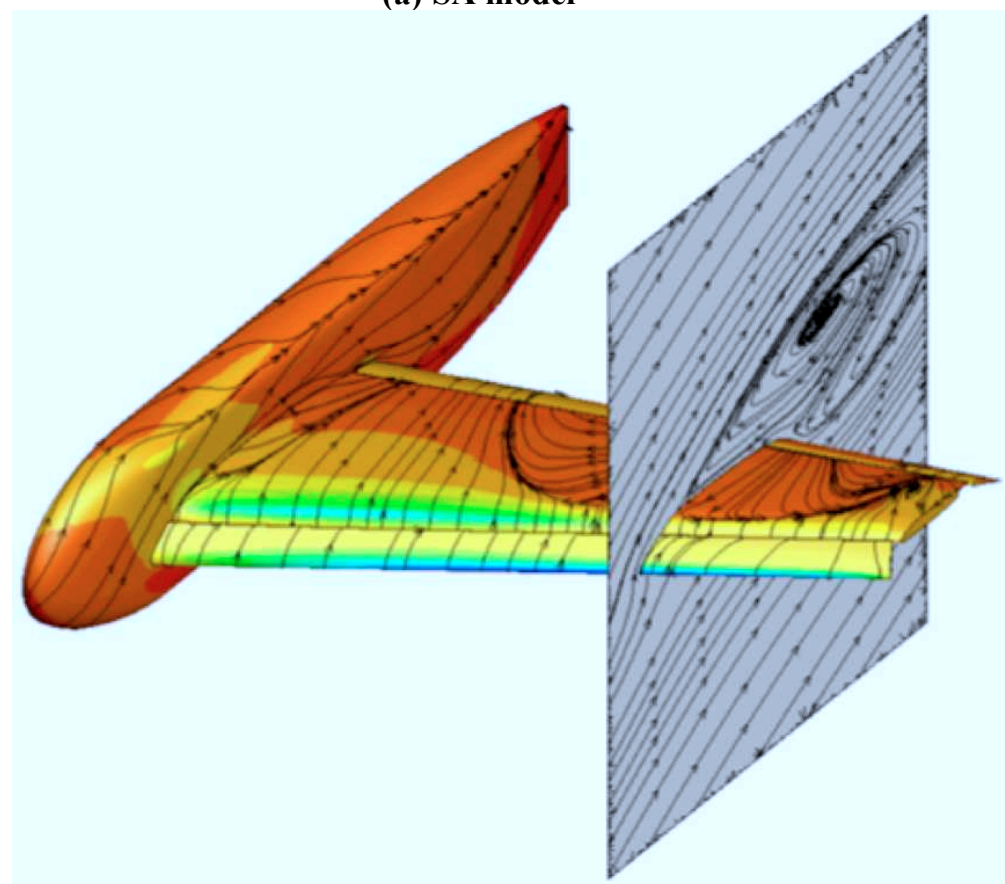

(b) SST model

Figure 15. Surface pressure contours and streamlines (projected on surface from grid points immediately above and in a streamwise plane at $70 \%$ span) from Configuration 1 solutions at angle-of-attack $34^{\circ}$ computed using two turbulence models. 


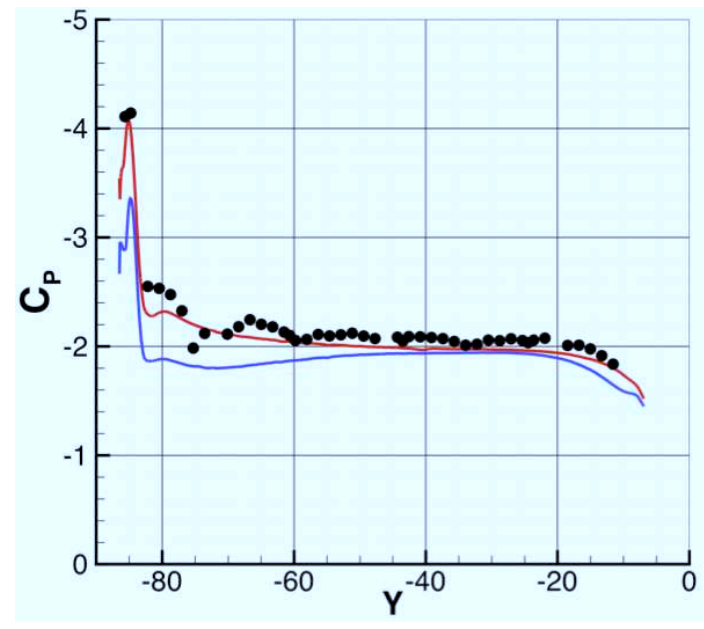

(a) $\alpha=6^{\circ}$

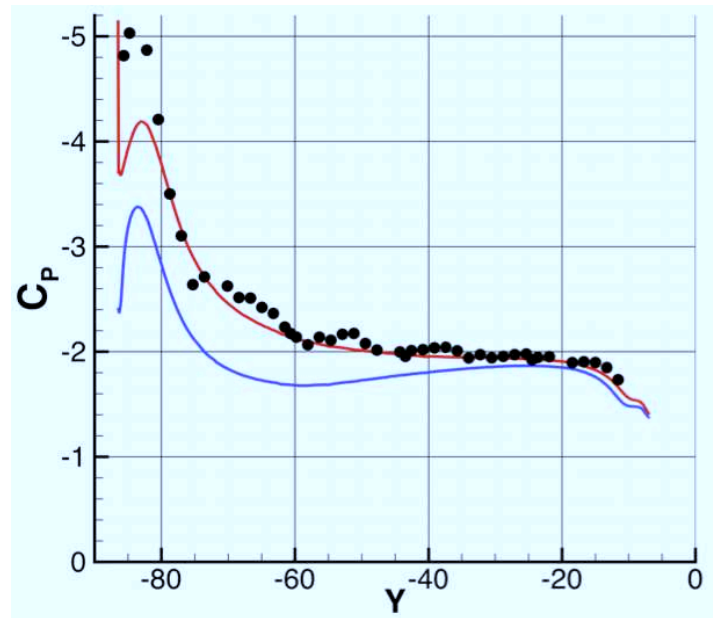

(c) $\alpha=21^{\circ}$

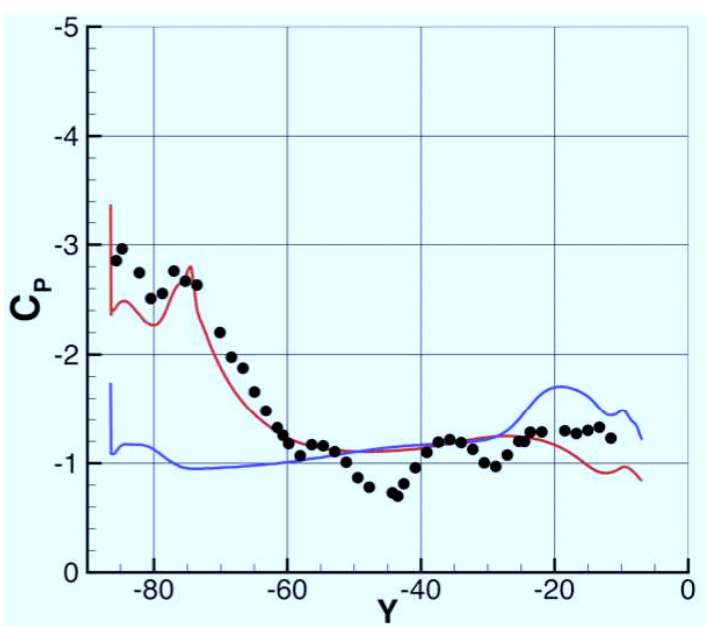

(e) $\alpha=34^{\circ}$

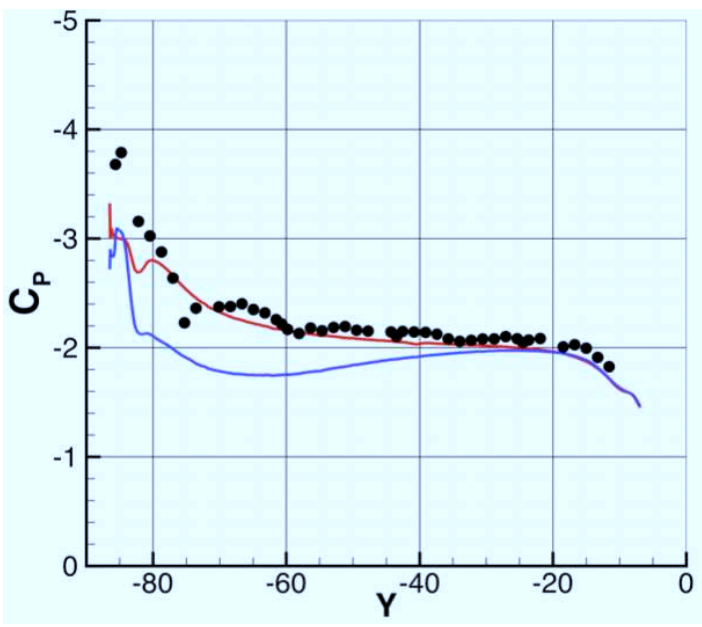

(b) $\alpha=13^{\circ}$

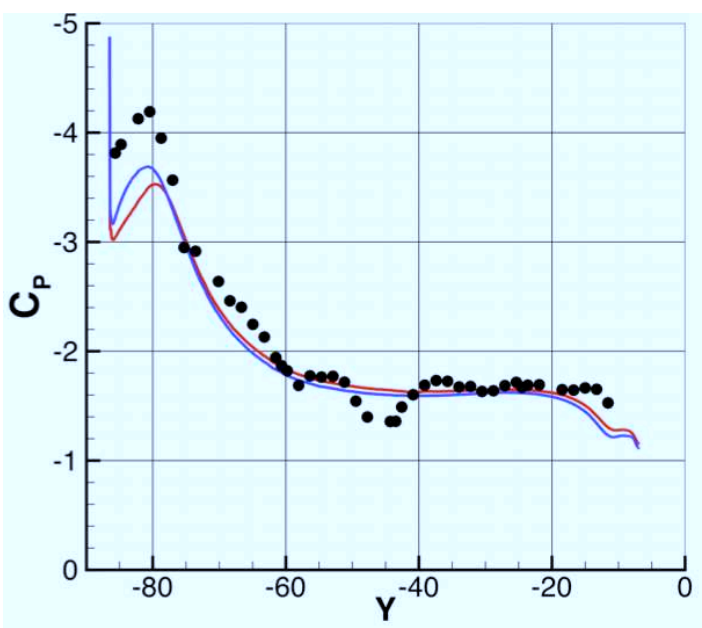

(d) $\alpha=\mathbf{2 8}^{\circ}$

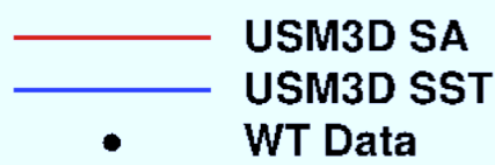

Figure 16. Comparison of fine grid SA and SST model computed and measured surface pressure at a location along the flap span (flapfwdspan station) on Configuration 1 at various angles-of-attack. 